\title{
LAS NECRÓPOLIS DE CISTAS DE "LAS ARQUETAS" (FRENEGAL DE LA SIERRA, BADAJOZ) Y OTROS RESTOS DE NECRÓPOLIS DE CISTAS EN LAS ESTRIBACIONES OCCIDENTALES DE LA SIERRA MORENA EXTREMEÑA
}

\author{
THE NECROPOLIS OF CISTS OF LAS ARQUETAS (FREGENAL DE LA SIERRA, BADAJOZ) \\ AND OTHER FUNERARY SITES IN EXTREMADURAN WESTERN SIERRA MORENA
}

\author{
por \\ JUAN JAVIER ENRÍQUEZ NAVASCUÉS \\ MARÍA JESÚS CARRASCO MARTÍN
}

\begin{abstract}
RESUMEN Se exponen los resultados de la excavación de dos necrópolis de cistas contiguas, con un total de 40 tumbas, cuyas características no se ajustan a los modelos hasta ahora detectados en suelo extremeño y que parecen marcar un territorio de paso entre la penillanura y la sierra como lugar de encuentro entre los focos de cistas del Bajo Alentejo, serranía onubense y penillanura extremeña.
\end{abstract}

\begin{abstract}
This work states the results of the excavation of two adjacent necropolis containing a total of 40 tombs whose characteristics differ with the models that have been detected till this moment in Extremadura and which seem to mark a certain cross-land between the areas of cistas of Bajo Alentejo, the Sierra of Huelva and the plain of Extremadura.
\end{abstract}

El conjunto arqueológico de Las Arquetas se enclava en las estribaciones septentrionales de Sierra Morena, dentro de la cuenca del río Ardila, cuyo cauce discurre a $2 \mathrm{kms}$. escasos en dirección N. La ubicación exacta es en las coordenadas $6^{\circ} 36^{\prime} 5^{\prime \prime}-38^{\circ} 17^{\prime} 3^{\prime \prime}$ de la hoja 875-II (Valverde de Burguillos), escala 1/25.000, del Mapa Topográfico Nacional (ed. 1983), a una altitud oscilante entre 380 y $390 \mathrm{~m}$. Administrativamente pertenece al término municipal de Fregenal de la Sierra, provincia de Badajoz, y es propiedad de la familia López Olea, a quienes debemos agradecer su amabilidad y ayuda desinteresada en todo lo relacionado con la realización de los trabajos de campo.

El paisaje de la zona en que se sitúa el yacimiento responde a las características de un relieve accidentado, con sierras cuarcito-pizarrosas que llegan a superar los $500 \mathrm{~m}$. de altitud, con el alto del 
Tocinillo (593 m.) como punto más elevado, y serratillas y lomas más suaves en torno a los $400 \mathrm{~m}$. Entre este relieve irregular se encajan vaguadas y pequeños valles surcados por riachuelos y arroyos de cursos casi siempre estacionales, entre los $300 \mathrm{~m}$. de altitud de las orillas del Ardila y los $350 \mathrm{~m}$. de algunos arroyos. Desde el punto de vista geológico, el terreno ofrece un sustrato precámbrico dominante de esquistos grauváquicos y áreas más restringidas de granitos, cuarcitas, calizas y pizarras cámbricas, que se incrustan entre los materiales precámbricos deformados y metamorfizados, con una densa red de fracturas (VVAA 1987a). Los suelos de la zona ofrecen un predominio de la tierra parda meridional sobre pizarras, con manchas de terra rossa y litosuelos sobre caliza, además de puntos con tierra parda meridional sobre roca intrusiva ácida (Guerra y Monturiol 1968). La vegetación ofrece la típica degeneración del bosque mediterráneo con predominio de encinas y alcornoques, transformado en amplias dehesas sinuosas que prácticamente llegan a la orilla de los cursos de agua, complementándose con diferentes especies de matorral: jara, retama, lentisco, etc. Como particularidad, se señala en este tramo del río Ardila la asociación fitoclimática de Asparageto y Rhamnetum (Rivas Goaday 1964: 475).

Con estos condicionantes físicos, la vocación económica de estas tierras es fundamentalmente ganadera, como en toda la comarca de Sierra Morena extremeña, aunque hasta hace algunos años determinadas tierras junto a los arroyos eran explotadas también con cultivos de secano, como ocurrió en las tierras bajas de la misma finca de Las Arquetas. En este sentido, hay que apuntar que los recursos hídricos son importantes, ya que abundan los manantiales, fuentes, arroyos y riachuelos, tributarios en buen número del Ardila, cuyas orillas sí presentan espacios aptos para la agricultura. El Ardila precisamente es el principal río de la zona, un río con una cuenca de $1837 \mathrm{kms}$. cuadrados en Extremadura, que discurre en este tramo con dirección NE-SW. muy regulado hoy por presas y pantanos. Con un caudal específico en la actualidad escaso, 2,22 litros por segundo y $\mathrm{km}$. cuadrado, tiene como principal carácter su irregularidad (García González 1994: 88). Por otra parte, no faltan recursos mineros notables explotados desde la Prehistoria, con algunas menas de oro y cobre, puntos muy concretos de estaño, pero sobre todo la comarca es rica en recursos férricos, que son los que mayor importancia e interés tienen en toda la zona SW. de la provincia de Badajoz (VVAA 1987 b).

Por último, hay que señalar que Las Arquetas (fig. 1) se encuentran en una zona de cruce de caminos, junto al Camino Viejo de Fregenal de la Sierra a Burguillos del Cerro, que atraviesa el Ardila por un vado existente a $2 \mathrm{kms}$. del yacimiento. En ese lugar tiene también su enlace el eje Bodión-Viar, que, salvando la sierra de Tentudía, conecta con la cuenca del Guadalquivir. En dirección E-O discurren así mismo diversas cañadas que desde Fregenal enlazan con las sierras de Huelva y se ramifican por este tramo del Ardila para llegar a la penillanura extremeña. Una zona por tanto destacada en este aspecto, como confluencia de pasos entre parajes de serranía y penillanura que durante muchos periodos históricos ha mantenido una gran importancia económica (Carmona 1993).

En resumen, el entorno de Las Arquetas conforma un territorio sinuoso de aprovechamiento fundamentalmente ganadero, próximo a caminos y rutas naturales que ahí vienen a confluir, rico en agua pero enormemente antropizado, lo que se refleja de manera muy importante en una vegetación pobre y degenerada del bosque mediterráneo con influencias atlánticas, con suelos de escasa potencia y pobres.

\section{EL YACIMIENTO}

La ubicación del yacimiento está espacialmente definida por la presencia de la sierra del Guijo al W. y el arroyo del Nogalito al E., encajado prácticamente entre ambos accidentes del terreno. El corte topográfico E-W. muestra cómo los restos arqueológicos se sitúan sobre un suave rellano al pie mismo 
de los inicios de la sierra, pero elevados aún sobre la cota del arroyo y tierras colindantes (fig. 1). Más al Este, el campo visual queda cerrado por los cerros de La Esgrima (568 m.) y El Rincón (546 m.), mientras al Norte está abierto hasta los cerros del Moro (432 m.) y del Castillo (473) sobre el Ardila, y al S. es algo más extenso pero limitado por distintas serratillas que superan los $450 \mathrm{~m}$.

El subsuelo está formado por pizarras en descomposición, muy húmedas, y el relleno vegetal es muy escaso, con huellas de tractores y faenas agrícolas que se apreciaban muy bien en algunas lajas de cistas y en parte del túmulo. También la presencia de un camino al pie mismo de las estructuras arqueológicas ha tenido como consecuencia la desaparición de parte el mencionado túmulo y la destrucción de algunas cistas, pero sobre todo ha desfigurado la topografía general del enclave del túmulo y primer cementerio de cistas.

Las estructuras arqueológicas encontradas se concretan en un túmulo que aprovecha una suave elevación del terreno y un conjunto a cistas al E. del mismo, separados por el citado camino, cuya construcción afectó, como se ha indicado, tanto al túmulo como a parte de las cistas. Del túmulo afloraban bien visibles algunas lajas de pizarra que denotaban la existencia de una estructura (fig. 2), mientras que la parte superior de las cistas era también visible en su mayor parte, aunque algunas habían sido rotas por el camino y otras desfiguradas, tal vez por acciones clandestinas. En total, al margen del túmulo, se constató la existencia de 26 tumbas, aunque es posible que ciertos hoyos profundos rodeados de fragmentos de lajas rotas y esparcidas denoten la existencia de algunas más que fueron destruidas. Por otra parte, a unos $150 \mathrm{~m}$. al NE. de este lugar y distante unos $50 \mathrm{~m}$. del camino se encontró otra necrópolis de cistas (fig. 3), con 14 tumbas, situadas en la vertiente $S$. de una suave elevación de $381 \mathrm{~m}$. de altitud, justo bajo la cima de la colina. Es decir, que no ocupa la parte alta de la misma, sino que las cistas se dispusieron inmediatamente debajo del pequeño rellano que la corona. Esta segunda necrópolis está atravesada por un sendero y, aunque al menos dos tumbas estaban alteradas parcialmente, no hay evidencias de ninguna destrucción, por lo que en general los daños sufridos han sido menores que en la necrópolis anterior.

\section{LAS NECRÓPOLIS DE CISTAS}

La primera necrópolis, a la que denominamos Arquetas 1 se encuentra junto al túmulo, al E. del mismo y separado de él por el camino (fig. 2). El número de cistas documentadas es de 26, de las cuales 5 se encontraron destruidas en casi su totalidad o con su fisonomía muy alterada $\left(n^{\circ} 2,9,18,21,23\right)$, por lo que el número real de tumbas excavadas fue de 21. Algún tipo de ajuar sólo proporcionaron 8 $\left(\mathrm{n}^{\circ} 1,6,7,8,10,11,19,26\right)$ y restos óseos o materia orgánica ninguna.

Las características morfotécnicas de las cistas de esta necrópolis (fig. 4-6) son en todos los casos las mismas, con una excepción, la $\mathrm{n}^{\circ} 26$. Se trata de cajas trapezoidales compuestas por cuatro lajas de pizarra, dos colocadas sobre el lado mayor en los laterales y otras dos, más pequeñas, colocadas de manera vertical en los lados menores, aunque no siempre, ya que en varios casos las lajas de los lados menores son más anchas que largas. Estas lajas, desbastadas, aparecen encajadas en unas cajas de cimentación abiertas en la pizarra con una profundidad de $15 \mathrm{cms}$. y en 13 casos existen piedras angulosas de pizarra y cuarcita, con diferentes tamaños, como refuerzos exteriores a manera de calzos y entibamientos $\left(\mathrm{n}^{\circ} 2,3,4,5,10,13,15,16,17,20,22,24,26\right)$, situados preferentemente en las esquinas. Por el interior las medidas dan también formas que en ningún caso llegan a ser rectangulares, con la roca pizarrosa del terreno como base, pero recubierta de una capa muy dura de entre 8 y $10 \mathrm{cms}$. de espesor compuesta por una amalgama de barro apelmazado con piedras pequeñas de 
cuarzo y cuarcita muy bien compactada. Precisamente en contacto con esta capa, en la parte superior de la misma y a veces ligeramente introducidos en ella, aparecieron los ajuares. El relleno de las cistas era a base de tierra granulosa del terreno, bien compactada en general, pero con multitud de raíces, hormigueros y nidos de otros animales que llegaban incluso a la base. En algunos casos también había trozos de piedra pizarrosa, sueltos y sin orden de colocación, que bien pudieran corresponder a desprendimientos de la cubierta. El sustrato base de pizarras, las raíces, los animales, las filtraciones etc. habían generado un ambiente de gran humedad en el interior de las cistas, el cual había afectado muy seriamente al estado de conservación de las cerámicas encontradas.

En cuanto a las lajas que delimitan las cajas de las cistas, son siempre de pizarra del propio terreno -con afloramientos abundantes en los alrededores y huellas de extracción de técnicas diferentes-, excepto algunos bloques de la aludida tumba 26. Las formas son irregulares pero tienden al rectángulo, acusan labores de desbaste y a veces ligero alisamiento. Las de los lados mayores de las cistas superan normalmente el metro de longitud por los cuarenta y cinco cms. de anchura, siendo la mayor una laja de la cista 6 que mide $155 \times 60 \times 20 \mathrm{cms}$. Las de los lados menores son también irregulares de tendencia rectangular, pero de menor tamaño y lógicamente no tan alargadas, en ocasiones más anchas que altas como ya se ha dicho. Oscilan entre $75 \times 51 \times 12 \mathrm{cms}$. de la mayor, que corresponde a la cista 5 , y $40 \times 50 \times 10 \mathrm{cms}$. de la menor, que es de la cista 3.

De distintas características es la tumba 26, excavada totalmente en la roca, con escasa profundidad, apenas $30 \mathrm{cms}$., y formada por tres lajas de pizarra delimitando otros tantos lados y el cuarto constituido por dos bloques de cuarcita y una laja de pizarra pequeña (fig. $6 \mathrm{n}^{\circ} 26$ ). Es la única tumba excavada en la roca, la única que no es a base de cuatro lajas, la única en la que fue utilizada la cuarcita y la única que no presentaba rastro alguno en superficie, salvo parte de la laja norte, que es la mayor. También es la única que no poseía la capa dura de barro apelmazado y piedras. A pesar de todo ello es de las 8 que proporcionaron algún tipo de ajuar.

La cubierta de las cistas estuvo constituida por otra gran laja de pizarra, que en el caso de la tumba $\mathrm{n}^{\circ} 1$ se encontró al lado mismo, documentándose otros ejemplos que habían sido quitados y tirados al lado, algunas veces rotos. Se trata de lajas ortostáticas rebajadas y algo alisadas por la parte interna y desbastadas por los lados, de forma oval alargada, siempre con una longitud que supera los $150 \mathrm{cms}$., con unas anchuras entre 90 y $100 \mathrm{cms}$. y grosor entre 20 y $30 \mathrm{cms}$. En cualquier caso en Arquetas 1 no se encontró ninguna en su sitio, aunque sí en Arquetas 2.

La orientación dominante de las cistas es la NO.-SE., que se da en $12(46,15 \%)$, seguida de la NE.-SO. con $6(23,07 \%)$, la N.-S. con $5(19,23 \%)$ y por último la E.-O. con $3(11,5 \%)$. Desde el punto de vista de la distribución espacial, sobre el plano (fig. 2) puede apreciarse cómo hay dos tumbas aisladas $\left(\mathrm{n}^{\circ}\right.$ 1 y 6) y cómo pueden señalarse seis agrupaciones formadas por un número variable de cistas entre dos y seis. El primer grupo, o grupo A, está formado por cuatro (2-5), ninguna con ajuar; el B por otras cuatro (7-10), tres de ellas con ajuar; el C también por cuatro (11-14), una con ajuar; el D por seis (15-20), con sólo una con ajuar; el E por dos (21 y 22) sin ajuar y el F por cuatro (23-26), con una sólo con ajuar que es la singular cista 26. Esta dispersión sin embargo no parece obedecer en principio a ninguna ordenación preconcebida ni de los grupos en conjunto ni de su estructura interna. No es posible así, de entrada, establecer un orden determinado en las agrupaciones en cuanto a la disposición de las tumbas, sus tamaños y ajuares.

La tipometría de las cistas, con las medidas internas y externas máximas de las cajas, profundidad a ras de suelo actual, orientación, presencia o no de ajuar y grupo se resumen en el siguiente esquema: 


\begin{tabular}{|c|c|c|c|c|c|c|}
\hline $\mathrm{N}^{\circ}$ & M. externas & M. internas & Profundidad & Orientación & Ajuar & Grupo \\
\hline 1 & $125 \times 98$ & $102 \times 74$ & 60 & E-W. & si & - \\
\hline 2 & 138 long. & 121 long. & — & NW-SE. & no & $\mathrm{A}$ \\
\hline 3 & $113 \times 62$ & $107 \times 58$ & 50 & NW-SE. & no & A \\
\hline 4 & $120 \times 72$ & $99 \times 65$ & 40 & NW-SE. & no & A \\
\hline 5 & $123 \times 90$ & $112 \times 73$ & 45 & NW-SE. & no & A \\
\hline 6 & $138 \times 100$ & $117 \times 79$ & 60 & NW-SE. & si & _ \\
\hline 7 & $110 \times 75$ & $99 \times 68$ & 45 & NW-SE. & si & $\mathrm{B}$ \\
\hline 8 & $120 \times 106$ & $113 \times 71$ & 43 & N-S. & si & $\mathrm{B}$ \\
\hline 9 & 125 long. & $\underline{-}$ & - & N-S. & no & B \\
\hline 10 & 130 long. & $\underline{-}$ & 35 & NW-SE. & si & B \\
\hline 11 & $125 \times 110$ & $103 \times 80$ & 46 & NW-SE. & si & $\mathrm{C}$ \\
\hline 12 & $120 \times 90$ & $105 \times 80$ & 42 & E-W. & no & $\mathrm{C}$ \\
\hline 13 & $127 \times 90$ & $110 \times 70$ & 38 & E-W. & no & $\mathrm{C}$ \\
\hline 14 & $117 \times 86$ & $112 \times 75$ & 42 & $\mathrm{~N}-\mathrm{S}$. & no & $\mathrm{C}$ \\
\hline 15 & $132 \times 75$ & $120 \times 70$ & 55 & NW-SE. & no & $\mathrm{D}$ \\
\hline 16 & $130 \times 93$ & $112 \times 77$ & 55 & NW-SE. & no & $\mathrm{D}$ \\
\hline 17 & $115 \times 80$ & $96 \times 62$ & 50 & NE-SW. & no & $\mathrm{D}$ \\
\hline 18 & $130 \times 78$ & - & 45 & NE-SW. & no & $\mathrm{D}$ \\
\hline 19 & $136 \times 90$ & $105 \times 58$ & 60 & NE-SW. & si & $\mathrm{D}$ \\
\hline 20 & $130 \times 100$ & $94 \times 68$ & 58 & NE-SW. & no & $\mathrm{D}$ \\
\hline 21 & - & 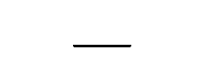 & - & NE-SW. & no & $\mathrm{E}$ \\
\hline 22 & $115 \times 90$ & $99 \times 65$ & 55 & NE-SW. & no & $\mathrm{E}$ \\
\hline 23 & - & - & - & N-S. & no & $\mathrm{F}$ \\
\hline 24 & $103 \times 70$ & $82 \times 56$ & 42 & NW. SE. & no & $\mathrm{F}$ \\
\hline 25 & $110 \times 73$ & $96 \times 62$ & 54 & $\mathrm{~N}-\mathrm{S}$. & no & $\mathrm{F}$ \\
\hline 26 & $110 \times 105$ & $105 \times 75$ & 27 & NW-SE. & si & $\mathrm{F}$ \\
\hline
\end{tabular}

La mayor de las cistas es la $\mathrm{n}^{\circ}$ 6, mientras la 24 es la menor de las completas. Ninguna es tan pequeña como para ser clasificada de "infantil" por su tamaño.

Las dos que no se encuentran en ninguna agrupación $\left(\mathrm{n}^{\circ} 1\right.$ y 6$)$ proporcionaron ajuar, pero no coinciden en la orientación. Por otra parte, ya se ha apuntado cómo dentro de las agrupaciones no hay ninguna que pueda señalarse o resaltarse en función de la conjunción de las variables tamaño-orientación-ajuar-situación. Así en el grupo A recordemos cómo ninguna tenía ajuar, pero en el B tres de cuatro, en el $D$ por ejemplo una sola de seis y en el $F$ sólo una que además corresponde a la $n^{\circ} 26$, que no destaca precisamente por tener una estructura cuidada o grande. Así, la relación entre las variables grupo-ajuar-orientación-tamaño no nos ha ofrecido asociaciones interpretativas identificables, es decir 
que, al menos en apariencia, la estructura de la necrópolis en función de los elementos apuntados no proporciona un modelo de comportamiento o disposición regular.

La segunda necrópolis -Arquetas 2- se ubica en la parte superior de la ladera Sur del suave promontorio aludido, bajo su parte más elevada (fig. 3). La componen 14 tumbas, que fueron excavadas, de ellas dos alteradas parcialmente $\left(\mathrm{n}^{\circ} 2\right.$ y 11$)$ y tres que habían sufrido algún daño por diferentes factores $\left(n^{\circ} 5,7,9\right)$. Once proporcionaron algún vestigio de ajuar.

Las características morfológicas, constructivas y tipométricas son las mismas que presentan las cistas de Arquetas 1 (fig. 7 y 8). No obstante, once tumbas proporcionaron ajuar (78,5\%), lo que indica una proporción mucho mayor a pesar de que en varios casos se trata de fragmentos cerámicos amorfos y pequeños sin valoración tipológica posible. Por otra parte, una de las cistas, la $\mathrm{n}^{\circ} 14$, se encontraba con la tapadera intacta, puesta en su lugar y otras tres con las cubiertas sobre las lajas, pero algo movidas y desplazadas de su posición original. Hay que reseñar también las pequeñas medidas de la cista 1 , cuyas dimensiones están muy por debajo de las del resto (fig. 7).

La orientación que presentan aquí las tumbas es también variada, pero dominan en número las E.-O. con cinco ejemplos, seguidas de las NO.-SE. con cuatro, las N.-S. con tres y las NE.-SO. se quedan en dos. Espacialmente pueden apreciarse dos agrupaciones y una tumba aislada (fig. 3), que es precisamente la $\mathrm{n}^{\circ} 14$, es decir la que tenía sin mover la cubierta. De las dos agrupaciones, la primera o grupo A está formada por 9 cistas ( $\left.n^{\circ} 1-9\right)$ cuya disposición es paracircular, envolviendo de manera un tanto anárquica, tanto por las posiciones de las cistas como por sus orientaciones, a las tumbas $n^{\circ} 1$-que es la de dimensiones más pequeñas- y a la $n^{\circ} 9$, que viene a ocupar una posición pseudocentral. La segunda agrupación o grupo B está formado por cuatro cistas ( $\mathrm{n}^{\circ}$ 10-13), más o menos alineadas de dos en dos.

Los rasgos de conjunto de las cistas de Arquetas 2 los resumimos en el cuadro siguiente, con los mismos encabezamientos que el expuesto para Arquetas 1

\begin{tabular}{ccccccc} 
N $^{\circ}$ & M. externas & M. internas & Profundidad & Orientación & Ajuar & Grupo \\
\hline 1 & $85 \times 55$ & $69 \times 42$ & 42 & NE-SW. & si & A \\
2 & $105 \times 90$ & $88 \times 63$ & - & NE-SW. & no & A \\
3 & $110 \times 90$ & $89 \times 70$ & 50 & N-S. & no & A \\
4 & $110 \times 98$ & $85 \times 78$ & 58 & E-W. & si & A \\
5 & $138 \times 100$ & $116 \times 74$ & 50 & E-W. & si & A \\
6 & $114 \times 100$ & $94 \times 75$ & 48 & E-W. & si & A \\
7 & $130 \times 100$ & $100 \times 76$ & 54 & NW-SE & si & A \\
8 & $105 \times 88$ & $73 \times 57$ & 55 & NW-SE. & si & A \\
9 & $130 \times 85$ & $107 \times 64$ & 48 & E-W. & si & A \\
10 & $120 \times 84$ & $91 \times 62$ & 45 & NW-SE. & si & B \\
11 & $110 \times 70$ & 104 long. & - & N-S. & no & B \\
12 & $124 \times 70$ & $110 \times 63$ & 48 & N-S. & si & B \\
13 & $140 \times 100$ & $109 \times 58$ & 52 & E-W. & si & B \\
14 & $114 \times 90$ & $102 \times 63$ & 50 & NW-SE. & si & -
\end{tabular}


A pesar de presentar esta necrópolis caracteres similares a Arquetas 1, resulta menos pobre aunque las relaciones grupo-ajuar-tamaño-orientación tampoco proporcionan una ordenación clara, con excepción del posible papel destacado de la cista 1, en el grupo A, singular por su tamaño, quizá algo relevante su situación, pero sobre todo por ser la única con un vaso decorado de tipología destacable dentro del conjunto de cerámicas. Por contra, la posición pseudocentral de la cista 9 no tiene reflejo claro en su ajuar, un vaso sencillo, su orientación es la mayoritaria en el grupo y su tamaño es grande pero hay otras mayores.

\section{LOS AJUARES}

En Arquetas 1 el número de tumbas que han proporcionado ajuar es bajo, 8 de $26(30,7 \%)$, y además pobre en cuanto a elementos. En cuatro tumbas el ajuar consistía en un solo vaso cerámico $\left(\mathrm{n}^{\circ} 1,8,10\right.$, 19), en dos un vaso cerámico y un elemento metálico pequeño ( $n^{\circ} 6$ y 26$)$, en una dos vasos $\left(n^{\circ} 7\right)$ y en otra tres $\left(n^{\circ} 11\right)$. Siempre los objetos aparecieron sobre la capa de barro duro y piedras o bien ligeramente incrustados en ella. En la tumba 26, que carecía de dicha capa, el ajuar se encontró sobre el suelo rocoso. En conjunto, los elementos no guardan una norma fija de deposición (fig. 4-6), de tal forma que se hallaron tanto junto a las esquinas como en los laterales o hacia el centro de la tumba.

En Arquetas 2 las tumbas con ajuar son clara mayoría, 11 de 14 (78,5\%), aunque reconocibles y estudiables son sólo seis. Únicamente una $\left(\mathrm{n}^{\circ} 13\right)$ ofreció más de un vaso cerámico, en concreto dos, mientras que otra de gran tamaño poseía, además de pedazos de un vaso irreconocible, un fragmento de cristal de roca amorfo $\left(\mathrm{n}^{\circ} 5\right)$. También otra cista $\left(\mathrm{n}^{\circ} 10\right)$ junto a fragmentos cerámicos contenía un prisma de cuarzo con restos de talla. La disposición de los objetos acusa la misma anarquía que en Arquetas 1 . Siempre se encontraron sobre la capa dura de barro y piedras (fig. 7 y 8 ). La tierra del vaso de la cista 14, que era la que apareció cubierta, ha sido sometida a análisis polínico, pero los resultados no arrojan sino especies degeneradas exponentes de la vegetación actual, no siendo considerada válida como muestra. También de la capa dura de la misma cista se tomaron muestras para análisis de composición, no disponiendo todavía de los resultados.

Tampoco en el caso de los ajuares, puestas en relación sus características tipológicas con la orientación de las tumbas, situación de los propios elementos de ajuar y tamaño de las cistas, surge regularidad alguna, sino por el contrario la ausencia de reglas y modelos o patrones. Esta anarquía se constata no sólo en ambas necrópolis por separado, sino incluso cuando se han unido y comparado juntos todos los datos de las dos.

Sintéticamente descritos, los elementos de ajuar encontrados son los siguientes.

\section{ARQUETAS 1}

Cista 1.- Vaso incompleto en forma de tulipa, con carena baja bien marcada, paredes cóncavas y bordes exvasados. Pasta escamosa de cocción que tiende a ser reductora y superficie gris bruñida. Diám. de la boca $9,8 \mathrm{~cm}$. Alt. $10 \mathrm{cms}$. (fig. 9).

Cista 6.- Vaso globular de paredes entrantes con mamelones bajo el borde. Pasta escamosa de cocción reductora y superficies pardas bien alisadas. Diám. de la boca 11,6 cms. Alt. $11 \mathrm{cms}$. (fig. 9)

- Aro en espiral de plata. Son tres espirales de hilo de sección circular. Diámetro máximo 3,8 cms. (fig. 9 y lám I). Analizado en Presur, dio como resultado una composición metalográfica de $96 \%$ de plata, $2 \%$ de cobre, $0,2 \%$ de hierro y resto impurezas. Nada de estaño ni de níquel, señalando una procedencia externa de la materia prima, cuanto menos de más de $10 \mathrm{kms}$. de radio alrededor del yacimiento. 
Cista 7.- Cuenco semiesférico de paredes entrantes, de pasta escamosa, cocción irregular y superficies pardas alisadas. Diám. de la boca $11 \mathrm{cms}$. Alt. 6,5 cms. (fig. 9)

- Cuenco de idéntica forma y caracteres que el anterior. Diám. de la boca 10,2 cms. Alt. 5,5 cms. (fig. 9).

Cista 8.- Cuenco semiesférico de paredes entrantes que no llega a la media esfera, de pasta escamosa, cocción reductora y superficies pardas muy bien alisadas. Diám. de la boca $12 \mathrm{cms}$. alt. 7,2 cms. (fig. 9).

Cista 10.- Fragmento de vaso con suave carena y una línea horizontal incisa, de pasta escamosa, cocción reductora y superficies grises bien bruñidas.

Cista 11. - Cuenco bajo de paredes entrantes, con pastas escamosas, cocción irregular y superficies pardas alisadas. Diám. de la boca $11,4 \mathrm{cms}$. Alt. 4,5 cms. (fig. 10).

- Vaso de cuerpo globular con cuello cilíndrico destacado, de pasta escamosa, cocción irregular y superficies pardas ligeramente bruñidas. Diám. de la boca $8,5 \mathrm{cms}$. alt. $9 \mathrm{cms}$. (fig. 10).

- Vaso globular con cuello indicado, de pasta escamosa, cocción irregular y superficies bruñidas. Diám. de la boca 12,3 cms. Alt. 17,2 (fig. 10). La base está quemada.

Cista 19. - Cazuela con carena bien marcada, de fondo redondeado, pared superior cóncava y borde saliente. Pasta escamosa de cocción reductora y superficies grises bruñidas. Diám. de la boca 14,7 cms. Alt. 6,2 cms. (fig 10). Parcialmente quemado en la base.

Cista 26.- Cuenco globular hondo de paredes entrantes, de pasta escamosa, cocción irregular y superficies pardas bien alisadas. Diám. de la boca 7,5 cms. Alt. 8,2 cms. (fig. 10).

— Fragmento de lámina de cobre muy deteriorada, quizá de una punta. Long. 2,8 cms. (fig. 10).

\section{ARQUETAS 2}

Cista 1.- Vaso pequeño de cuerpo bitroncocónico con carena central destacada y borde saliente, con decoración a base de bandas de puntos impresos, una bajo el borde, dos encima de la carena y sobre ésta líneas impresas. Pasta granulosa, cocción que tiende a reductora y superficies bruñidas. Diám. de la bocas $8 \mathrm{cms}$. Alt. $6 \mathrm{cms}$. (fig. 10 y lám. I). Hay algunas zonas quemadas.

Cista 4.- Fragmento cerámico amorfo.

Cista 5.- Fragmento cerámico amorfo.

- Fragmento de cristal de roca de $0,5 \times 0,7 \times 0,6 \mathrm{cms}$.

Cista 6.- Borde de cuenco de paredes entrantes de pasta escamosa, cocción irregular y superficies rojizas bien alisadas.

Cista 7.- Cuenco bajo de paredes entrantes, de pasta escamosa, cocción irregular y superficies rojizas parcialmente quemadas. Diám. de la boca $11,2 \mathrm{cms}$. Alt. $6 \mathrm{cms}$. (fig. 8).

Cista 8.- Fragmento cerámico amorfo.

Cista 9.- Cuenco globular de paredes entrantes, pasta escamosa, cocción irregular y superficies pardas bien alisadas. Diám. de la boca $5,8 \mathrm{cms}$. Alt, 6,5 cms. (fig. 8).

Cista 10.- Diversos fragmentos cerámicos amorfos muy deteriorados, de color pardo y caracteres técnicos idénticos al resto de cerámicas.

- Pequeño prisma de cuarzo con restos de talla que mide $2,5 \times 1,5 \times 2,5 \mathrm{cms}$.

Cista 12.- Cuenco semiesférico de pasta escamosa, cocción irregular y superficies parduscas alisadas. Diám. de la boca 9,8 cms. alt. 6,7 cms. (fig. 8). 
Cista 13.- Cuenco de paredes entrantes que no llega a la media esfera, con las pasta escamosa, cocción reductora y superficies pardo-negruzcas bien alisadas. Diám. de la boca $12 \mathrm{cms}$. Alt. 7,8 cms. (fig. 8). Parcialmente quemado.

- Vaso de cuerpo globular con cuello marcado y borde ligeramente exvasado. Pasta escamosa, cocción irregular y superficies pardo-negruzcas bruñidas. Diám. de la boca 7,7 cms. Alt. 9,5 cms. (fig. 8).

Cista 14.- Pequeño cuenco semiesférico de pasta gruesa granulosa, cocción irregular y superficies pardo-negruzcas mal alisadas. Diám. de la boca 7,2 cms. alt. $4 \mathrm{cms}$. (fig. 8). Parcialmente quemado.

Hay que destacar la uniformidad en las características técnicas de las cerámicas, con un claro dominio de las pastas escamosas y de las cocciones que tienden a reductora, así como del tratamiento de las superficies a base de bruñido en una mayoría de los vasos. De igual forma el tamaño, casi siempre pequeño o mediano, con sólo un vaso grande (Arq. 1: 11). Por otra parte, la espiral de plata nativa de procedencia extraña a la zona.

Importante puede ser el detalle que presentan diversas vasijas de estar parcialmente quemadas, algo que tal vez haya que poner en relación con rituales, puesto que en ninguna cista hay resto alguno de fuego ni en las lajas ni en el suelo duro ni en la tierra de relleno. Se tuvieron que depositar por tanto una vez quemadas, pero sólo parcialmente y con preferencia en la base, aunque no en todos los vasos se aprecian claramente huellas de exposición al fuego

Dentro de los elementos de ajuar, el más utilizado resulta ser el cuenco pequeño o mediano de paredes redondeadas, que está presente en 10 ajuares de los 13 susceptibles de estudio, con un total de 11 piezas de las 17 valorables tipológicamente. En cinco cistas (Arq. 1: 8; Arq. 2: 7, 9, 12,14) el ajuar está compuesto única y exclusivamente por uno solo de estos cuencos ( $38,4 \%$ de las cistas con ajuar estudiable), pero en las tres cistas en que hay más de un elemento cerámico (Arq. 1: 7 y 11; Arq. 2: 13) también está presente el cuenco de paredes redondeadas de igual manera que en las otras dos en que hay elementos metálicos (Arq. 1: 6 y 26). Es decir en los diez ajuares apuntados antes, que en términos absolutos suponen el $76,92 \%$ de todos ellos.

Las formas carenadas están documentadas en dos cistas como único elemento de ajuar (Arq. 1: 1 y 19), mientras que vasos decorados sólo hay uno (Arq. 2: 1) de especial tipología dentro del conjunto cerámico (fig. 10 y lám. I), por lo que tal vez deba ser considerado un objeto relevante, por otro lado asociado a la cista más pequeña de ambas necrópolis. Por último, los vasos pequeños de cuerpo globular y cuello desarrollado aparecieron en dos cistas, en ambos casos asociados a cuencos (Arq. 1: 11; Arq. 2: 13) y en uno de ellos a otro vaso mayor.

Como elementos metálicos sólo dos objetos pequeños acompañando a sendos cuencos, uno un objeto de cobre muy deteriorado, que por su estructura laminar bien pudo pertenecer a una punta sin posibilidades de valoración tipológica, y un aro serpentiforme o anillo en espiral de plata nativa. De piedra hay que anotar el pequeño fragmento de cristal de roca (Arq. 2. 5) y el prisma de cuarzo con restos de talla (Arq. 2: 10).

La novedad que algunos de estos elementos de ajuar suponen dentro de la todavía parca y muy parcial documentación de los enterramientos en cistas de la Cuenca media del Guadiana, hace conveniente su valoración tipológica tradicional en función del marco referencial en el que se integran. Por ello vamos a realizar algunas consideraciones generales sobre los mismos.

Dentro de los cuencos de paredes redondeadas pueden señalarse algunas variantes de interés. A). En primer lugar los cuencos semiesféricos pequeños, presentes como único elemento de ajuar en dos cistas (Arq. 2: 12 y 14). B). En segundo los cuencos globulares de paredes entrantes presentes en tres (Arq. 1: 6 y 26; Arq. 2: 9), en una como único ajuar y en las otras dos asociadas a los elementos metálicos. C). Muy parecidos son tres cuencos de paredes entrantes cuyo cuerpo sin embargo es menor 
que la media esfera, presentes en dos cistas, una con dos ejemplos (Arq. 1:7) y la otra con un vaso de cuello destacado (Arq. 2: 13). D). Por último, los cuencos bajos y achatados de paredes entrantes, que en dos cistas están solos (Arq. 1: 8; Arq. 2: 7) y en otra junto a dos vasos más (Arq. 1: 11).

Los cuencos pequeños y medianos de perfiles globulares y semiesféricos aparecen por tanto con una buena representación y con formas idénticas a las del Calcolítico. Mayor interés tienen sin embargo los cuencos bajos y achatados de paredes entrantes (D), de tradición también anterior (Caro 1989: 98), pero que no están documentados en las cistas extremeñas hasta ahora publicadas (Gil Mascarell y otros 1986; Pavón y otros 1993), aunque sí, al igual que los otros cuencos, están presentes en la estratigrafía de Alange, sobre todo en los niveles del Bronce pleno (Pavón 1995a). Algunos ejemplares parecidos a éstos se conocen en el Sur de Portugal, como en Poio (Portimano) (Schubart 1975a: t. 1), también en las cistas sevillanas de Chichina (Fernández Gómez y otros 1976: figs. 6 y 10) y en la fase 1 de Setefilla (Aubet y otros 1983: figs. 15 y 18), pero sobre todo en un buen número de cistas de la sierra onubense: tumba 1 de Becerrero II, tumba 1 de Becerrero V, Beas, cista 7 de La Parrita etc (Del Amo 1975: 1. 101, 110, 121; Pérez Macías y Frías 1990), donde su presencia resulta muy representativa, acompañando casi siempre a otros vasos. En esta zona, dentro de la estratigrafía de El Trastejón (Zufre) se integrarían en la forma 4, bien representada en la fase antigua y considerada forma típica del Bronce pleno (Hurtado y García Sanjuán 1994: 248). Su morfología y perfil les acercan a los cuencos de paredes entrantes de cuerpo inferior a la media esfera, cuya relación anchura/altura es muy similar, conformando una variedad que también es muy corriente en las cistas del SO. (Pérez Macías y Ruiz Delgado 1986). Así, ambas variantes de cuencos bajos con bordes entrantes y diámetro máximo situado en el tercio superior de la pieza suponen el $35,29 \%$ del total de las piezas cerámicas reconocibles tanto en Arquetas 1 como en 2., lo cual proporciona una aproximación como indicador de la representatividad de estos cuencos.

La cazuela carenada de las cista 19 de Arq. 1 recuerda formas de Atalaia, pero más evolucionadas, así como a los vasos carenados de las tumbas 1 de Becerrero II y IV (Del Amo 1975: 1. 100 y 109), aunque en el primer caso tiene el perfil menos acusado y en ambos casos el tamaño de los ejemplares es sensiblemente más pequeño. No obstante, tiene una referencia importante en la fase I del corte 3 de Setefilla (Aubet y otros 1983: figs. 18), dentro del Bronce pleno, y en la estratigrafía de Alange, donde guarda relación con las cazuelas medianas de la fase Solana IIA (Pavón 1993: 162), también atribuida al Bronce pleno y contemporánea, según dicho autor, al desarrollo de las cistas conocidas de la provincia de Badajoz.

El vaso carenado bruñido de la cista 1 de Arq. 1 presenta como particularidad la relación entre el diámetro de la boca y la altura, con $10 \mathrm{cms}$. esta última, lo que le aleja de los vasos tipo Atalaia, y aunque por definición podría asimilarse a la forma 5 del Trastejón (Hurtado y García Sanjuán 1994: 256), resulta más alto y estrecho. Así, a pesar de sus reminiscencias argáricas (Schubart 1975 b), ciertamente su forma se asemeja a las llamadas jarras de diversas tumbas de Huelva y sur de Portugal (Del Amo 1975: 1. 99, 103; Schubart 1965: figs. 11, 12, 19), aunque es más pequeño y carece del asa que define dichas piezas. Por ello, tal vez su forma de tulipa pudiera valorarse más bien como una herencia de la tradición megalítica occidental, que con distintas variantes en cuanto a la carena y concavidad del cuerpo superior se documenta en el Bronce pleno del suroeste peninsular, siendo en este sentido relacionable con la forma 6 señalada por Caro para el Cerro Berrueco (Caro 1989: 99 y 112).

Los vasos globulares con cuello destacado son un elemento bien conocido en las cistas y poblados de la Edad del Bronce del suroeste: cistas del Bajo Alentejo y Algarve (Schubart 1975a), Huelva (Del Amo 1975), Sevilla (Fernández Gómez y otros 1976), la propia Extremadura como es el caso de la de Berlanga (Gil Mascarell y otros 1986); poblados de Setefilla (Aubet y otros 1983), El Trastejón (Hurtado y García Sanjuán 1994), Alange (Pavón 1995a), Cerro Berrueco (Caro 1989: 115) etc. Pero en dos casos se trata de tamaños ostensiblemente más pequeños y proporcionalmente más anchos de boca, aunque 
hay algunos ejemplares de contextos funerarios paralelizables, como el vaso también pequeño de la tumba 7 de Becerrero I (Del Amo 1975: 1. 98).

El único vaso decorado pertenece al tipo que Schubart denominó "vaso con zonas horizontales" (Schubart 1971: 156) al que consideró característico de su Bronce II (Schubart 1975: figs. 26), un tipo con ciertas variantes en cuanto a la disposición de la decoración, bien documentado en necrópolis del Algarve como Sta. Vitoria, Medara o Peral y también en la zona de Sines, por ejemplo en las cistas 19 de Provença, 12 de Quiteria y 5 del monumento I de Pessegueiro (Tavares y Soares 1979: 135). Resulta así un elemento de ajuar más propio de la cultura material de las cistas bajoalentejanas y algarvias que de las andaluzas, que además de un valor cronológico relativo tiene esa dispersión apuntada que hace de este ejemplar el más oriental de los publicados hasta el momento. De esta manera, su presencia en Las Arquetas, donde es el único vaso decorado encontrado, puede revestir un significado relevante como objeto destacado, hecho éste que puede verse reforzado si tenemos en cuenta que la cista 5 del monumento I de Pessegueiro proporcionó un vaso idéntico, el único de las cistas que lo componían, y la única además con unas medidas muy pequeñas, tal y como ocurre con la cista 1 de Arquetas 2.

$\mathrm{El}$ aro de plata responde mejor, por su forma y dimensiones, a un adorno en espiral como los conocidos en oro del Bronce medio y final (Ruiz Gálvez 1984: 385 y ss.) que a un anillo en forma de aro como los así considerados por Schubart procedentes del Argar y de algunas cistas del SO., como la de Cabañas en Huelva y otras del Algarve y Alentejo (Schubart 1975: K. 30). Tampoco a una aguja como apuntó Del Amo para el alambre de plata, pero de sección poligonal, de la tumba 1 de Becerrero IV (Del Amo 1975: 142). En cualquier caso la plata es un elemento bien documentado en las comunidades del SO. que utilizan el sistema funerario de cistas y no faltan incluso escorias de fundición en algunas de ellas como en la 6 de La Parrita en Huelva (Pérez Macías y Frías 1990: 13). Plata utilizada para adornos y que en el caso de la de Las Arquetas, con $3,8 \mathrm{cms}$. de diámetro, no puede ser clasificada como anillo, sino como adorno en espiral.

\section{CARACTERIZACIÓN DE LAS NECRÓPOLIS}

Las características generales de las necrópolis de Las Arquetas definen un modelo estructural y ritual que presenta diversas particularidades que las hacen diferentes de las hasta ahora conocidas y publicadas de la Cuenca media del Guadiana (Gil Mascarell y otros 1986; Pavón y otros 1993). Cierto es que el conocimiento del fenómeno funerario de las cistas en dicha cuenca es todavía muy parcial e incompleto, centrándose además de manera fundamental en las estribaciones de la comarca de Tierra de Barros, pero de la veintena larga de lugares apuntados en la bibliografía ninguno de ellos se ajusta por ahora a las particularidades que Las Arquetas ofrecen. Así, en primer lugar hay que recordar la propia integración del yacimiento en un medio físico de sierra y no de penillanura, con una ubicación al pie mismo de una alineación destacada dentro del relieve accidentado de la zona (fig. 1). Se trata además de las estribaciones de las sierras onubenses en su vertiente más septentrional, por lo que las variables geográfica, espacial en sentido amplio y medioambiental las acercan a los núcleos de cistas de las sierras de Huelva, no siendo por otra parte las únicas variables que apuntan en dicha dirección. Por ello, y por otros rasgos apuntados y que más tarde comentaremos, tal vez el espacio cultural en el que hay que integrar Las Arquetas esté más cerca del que conforman los enterramientos en cistas de las sierras onubense y parte más occidental del Bajo Alentejo -con las sierras como eje articulador- que del espacio geográfico natural del Guadiana extremeño. Y ello con el importante matiz de integrarse dentro de una zona concreta de paso y enlace como parece deducirse de su situación entre la margen izquierda de la cuenca del Ardila, que es el camino natural hacia el tramo descendente del Guadiana, y las 
primeras estribaciones de las sierras de Huelva. Es decir, en un verdadero pasillo, a muy pocos kms. de la divisoria de aguas entre las cuencas del Guadiana y Guadalquivir y en el inicio de la transición entre las formaciones de sierra cerrada y las estribaciones de las mismas que sirven de tránsito a la penillanura a través de Burguillos del Cerro y Salvatierra. Es además un punto de enlace entre las áreas con recursos de cobre de las sierras de Huelva y la zona cuprífera de La Lapa-Feria, que encuentran por esta zona su mejor vía de conexión geográfica. En términos de distancia Las Arquetas están en un punto equidistante entre el corazón de Tierra de Barros y el núcleo de la sierra de Aracena, pero más cerca del medio físico y capacidad económica de la sierra que de la penillanura. No se trata además de las únicas necrópolis de cistas de la comarca, que de esta manera reafirman una implantación como fenómeno cultural importante tanto hacia el Norte como hacia el Sur y Oeste, aunque dentro de unas pautas de poblamiento aún desconocidas.

Por otro lado las raíces, nidos animales y filtraciones de tierra han impedido análisis polínicos y de composición fiables del contenido de los pocos vasos enteros, por lo que carecemos de datos paeloambientales de este yacimiento y de toda la comarca para los milenios III y II a. C. que puedan informar sobre el paisaje y la acción humana sobre el mismo, hecho éste que impide matizar adecuadamente la apuntada relación potencial con las áreas de las sierras onubenses.

Pero dentro de las variables de análisis intrínsecas hay que destacar en primer lugar cómo los sistemas constructivos que presentan Las Arquetas coinciden con el resto de cistas del actual territorio extremeño en que son estructuras casi siempre compuestas por una caja trapezoidal, a base de cuatro lajas, a veces con entibamientos, y una cubierta monolítica, como también ocurre en las de Huelva. Pero en las Arquetas sólo la tumba 26 de Arquetas 1 está excavada en la roca y el suelo de todas las sepulturas, con excepción de la citada, está formado por una capa de barro y piedrecitas de entre 8 y $10 \mathrm{cms}$. de espesor, aspecto éste ausente en las cistas extremeñas publicadas y también en las onubenses, pero documentado en algunas tumbas de Sines (Tavares y Soares 1981), donde hay también otros tipos de suelos formados por lajas de piedra o bien arena como ocurre en algunas de Portimao en el Algarve (Varela y otros 1986: 63). Por otra parte, la distribución espacial de las tumbas permite señalar en Las Arquetas muy pocas cistas aisladas y una clara mayoría integrada en agrupaciones de corto número, lo cual se ha señalado para diversas necrópolis de Huelva (Del Amo 1993: 171) y también para el sur de Portugal, aunque aquí no se han detectado las estructuras tumulares circulares o rectangulares como las del denominado grupo Sines (Tavares y Soares 1979: 147) o las de Ourique y otras zonas del Algarve (Schubart 1965). En cualquier caso, a este respecto hay que tener presente el corto número de cistas de las necrópolis conocidas en Extremadura, por lo que sólo es contrastable esta falta de agrupaciones dentro de la misma necrópolis con la dispersión no grupal apuntada para las 25 cistas de Las Minitas en Almendralejo (Pavón y otros 1993: 12).

Pero es en los aspectos rituales donde se advierten las más importantes diferencias con respecto a la cistas extremeñas conocidas y mayor relación con las de la sierra onubense y algunas otras del sur de Portugal. Hay que recordar cómo ninguna proporcionó resto alguno de cadáveres, al igual que ocurre por ejemplo en El Becerrero, El Castañuelo o La Parrita en la sierra de Huelva, Pesegueiro en Sines y Atalaya en Ourique. Y junto a esta cuestión aún de difícil interpretación (Del Amo 1993: 172), pero muy importante a pesar de ello por constituir un rasgo definidor de comportamiento, tampoco los ajuares presentan reglas fijas o regularidad en su disposición, al contrario de lo que ocurre en ciertas cistas como las de Las Minitas (Pavón y otros 1993: 19). Por otra parte, no han aparecido restos arqueológicos fuera de las cistas, pese a que se procedió a limpiar el terreno. No hay así estructuras de hábitat en las inmediaciones de las cistas como en algunos monumentos de Sines (Tavares y Soares 1979: 147), en Chichina (Fernández Gómez y otros 1976: 351) o en Las Minitas (Pavón y otros 1993) ni estructuras de combustión de carácter ritual como las así interpretadas de Vinha do 
Casao (Varela y otros 1986: 89). Tampoco materiales dispersos como los hallados en las extremeñas de Las Palomas (Gil Mascarell y otros 1986: 34). Es decir, no se han encontrado restos de actividades en el exterior de las sepulturas, hecho éste que si bien en Arquetas 1 pudiera deberse a una alteración del terreno debido a las faenas agrícolas no ocurre así en Arquetas 2, donde sólo el sendero que pasa por el lugar pudo producir, y muy localizadamente, alteraciones capaces de hacer desaparecer huellas de actividades antrópicas.

Destacable resulta el hecho de que varias vasijas presentan restos de exposición al fuego, sobre todo en la base, como si previa a su deposición en las cistas hubiesen formado parte de algún ritual en el que el fuego desempeñaba también un papel importante. No todos los vasos presentan quemaduras parciales, pero la mayoría de los mejor conservados sí y, como se comentó más arriba, ello no debió ocurrir dentro de las cistas puesto que en ellas no hay señal alguna de fuego.

Por otra parte, los ajuares se integran dentro de la misma dinámica tipológica, variabilidad deposicional y frecuencia de ausencia/presencia que el resto de necrópolis de cistas de todo el SO. Hay que recordar así cómo no hay ajuares diferenciables en función de la situación, tamaño y orientación de las tumbas, al igual que se ha constatado en las necrópolis portuguesas con estructuras tumulares (García Sanjuán 1994: 218 y 220). En cuanto a su frecuencia, tal y como se ha indicado más arriba, el $30 \%$ de las cistas de Arquetas 1 proporcionó restos de ajuar, porcentaje que se eleva considerablemente en Arquetas 2 hasta llegar al 78,5\%. Es decir relativamente bajo en Arquetas 1 y alto en Arquetas 2, estableciéndose en este sentido una diferencia cuantitativa notable entre una y otra que sin embargo no se corrobora en el aspecto cualitativo, porque en Arquetas 1 cuatro de ocho contenían más de un vaso y en Arquetas 2 tres de seis, pero de las tres dos con un pequeño objeto lítico junto al vaso. Además las dos únicas piezas metálicas corresponden a cistas de Arquetas 1, de igual manera que la única con tres objetos. Cierto también que el único vaso decorado y destacable corresponde a Arquetas 2, por lo que pueden señalarse objetos suntuosos en ambas necrópolis, pero con items metálicos la que menos ajuares tiene. Faltan de cualquier modo análisis de variabilidad sobre este sistema distributivo intragrupal en las necrópolis de cistas del SO. (García Sanjuán 1994), pero en principio la desigualdad distributiva entre ambas necrópolis parece ser más aparente que real. En este sentido la separación espacial entre Arquetas 1 y 2 , es decir el hecho de utilizar espacios cercanos pero bien diferenciados, no tiene por qué obedecer a desigualdades sociales sino que puede estar más en consonancia con otras variables de la manera o modo de articular la estructura social ante el hecho de la muerte -bastante oscura como de por sí expone la ausencia total de restos de cadáveres- que de la plasmación de un sistema jerárquico.

Distinta es la cuestión de una jerarquización social reconocible, entre otras variables, por el uso de objetos de prestigio como ajuares, tema con enfoques y valoraciones a veces contradictorias (García Sanjuán 1994). Pero al margen de posicionamientos teóricos, no puede pasar desapercibida la repartición no igualitaria de los ajuares, que en Las Arquetas va desde ninguno hasta tres objetos y desde un vaso pequeño de mediocre factura a un objeto de plata, por lo que cuantitativa y cualitativamente se aprecian diferencias que habría que explicar social o, en su defecto, ritualmente. En Arquetas 1 destaca la cista 11 con un vaso mediano y dos pequeños y un sistema muy concreto de deposición: el vaso pequeño dentro del más grande y éste cubierto con el cuenco. También la cista 7 (dos cuencos) y sobre todo la cista 26 , con un vaso y un objeto muy deteriorado de cobre, y la 6 , donde hay que mencionar el anillo de plata nativa, cuya materia prima no procede de los alrededores del yacimiento, lo que implica su consideración como bien adquirido y diferenciador. En Arquetas 2 el vaso decorado de la cista 1, que ya en su paralelo formal de la tumba 5 del monumento de Pessegueiro 1 aparece asociado a una tumba pequeña -y también sin cadáver- de dimensiones muy similares a la de la cista de Arquetas, y que es en la necrópolis portuguesa el único vaso cerámico de dicho monumento. O sea que al margen 
de posibles reutilizaciones, la cista 11 de Arq. 1 incluye un ajuar colocado en un solo momento a base de tres piezas no iguales y la 6 un adorno como símbolo de propiedad adquirida y no comunal, mientras en Arq. 2 el vaso decorado es un elemento diferenciador como en el monumento 1 de Pessegueiro, al igual que lo es el vaso gallonado en Las Minitas (Pavón y otros 1993), que dentro de Tierra de Barros resulta singular igual que éste de las Arquetas en el territorio de la Sierra.

La valoración tipológica de los ajuares ofrece unos referentes cronológicos que se mueven de manera uniforme en el llamado Bronce pleno, que equivaldría al Bronce II del SW. de Schubart pero con una serie de matizaciones cronológicas importantes (Pavón 1995b). En base a dichos referentes no podemos hablar de fases en ninguna de las dos necrópolis ni de desfases entre una y otra. Ya se ha puesto de relieve también la uniformidad tecnológica de la gran mayoría de las cerámicas y el criterio de considerar las centrales más antiguas que las periféricas no encuentra apoyo claro aquí como tampoco las diferencias de orientación, tamaños o sistemas constructivos, que son igualmente uniformes y ajustados a las mismas características de material, disposición y tratamiento. Sólo la cista 26 de Arquetas 1 ofrece rasgos diferenciadores y podría ser considerada un añadido por su situación, no tanto por su ajuar, que resulta poco expresivo en términos cronológicos, pero también pudiera ser la primera y marcar un lugar funerario que luego se desarrolló, con otras características formales, dejándola en la periferia. No hay así argumentos estratigráficos y los socorridos paralelismos faltan para ir más allá en el hecho diferencial que la citada cista expone. En teoría tampoco hay argumentos para hablar de una dilatada utilización de la necrópolis, puesto que no se advierten cambios de comportamiento en el registro y falta una visión más amplia del territorio para matizar y el contraste con poblados cercanos de la misma etapa.

No obstante, la valoración tipológica de los ajuares sirve también para puntualizar otras cuestiones. Así los cuencos achatados ya hemos visto cómo alcanzan en las cistas de Huelva mayor representatividad que en otras áreas, lo que de algún modo viene a reforzar las conexiones con dicha zona a la que también se vincula en cuanto a módulos constructivos, disposiciones espaciales, contextos materiales, aspectos rituales y rasgos medioambientales. Al igual que allí, la tradición de la cultura material calcolítica no adquiere un protagonismo tan destacado como en las cistas conocidas de la penillanura extremeña, a pesar de que tampoco puede perderse de vista que Las Arquetas 1 y 2 constituyen al unísono el mayor conjunto de cistas excavado en la actual región extremeña. Pero no faltan tampoco rasgos característicos en la estructura de ambas necrópolis que no se conocen hasta ahora en las de Huelva, como la capa de barro duro y piedras del suelo de las cistas o el vaso decorado de la cista 1 de Arquetas 2, rasgos ambos que en el Sur de Portugal, sobre todo en el llamado grupo Sines, sí se tienen documentados. Este matiz diferenciador tanto en la estructura como en algunos elementos de la cultura material puede interpretarse en función de la situación geográfica de Las Arquetas, que como se apuntó constituye un punto de paso desde la sierra a la penillanura donde enlaza, a través del Ardila, un pasillo al Oeste que carece de otros caminos o vías naturales desde el cauce del Guadiana.

El reciente estudio de Pavón sobre el II milenio en Extremadura señala al Guadiana como vía de comunicación con el sur de Portugal y camino de penetración a su cuenca media de elementos considerados característicos del foco portugués del Bronce del SO. (Pavón 1995 a). Si se acepta dicha propuesta habría que relacionar esa vía del Guadiana con la llegada de elementos y relaciones con el sur portugués y apuntar el papel del Ardila como ramal hacia los inicios del área de sierra, donde llegarían a confluir con el foco de las sierras onubenses. Las Arquetas podrían marcar por consiguiente un punto de encuentro, pero también una vía de penetración hacia la penillanura central de la cuenca media del Guadiana. Recordemos cómo es la zona que aglutina los pasos entre las zonas mineras de la serranía onubense y las del entorno de Tierra de Barros. 


\section{OTRAS NECRÓPOLIS DE CISTAS DEL ENTORNO}

En el entorno de Las Arquetas se ha podido reconocer la existencia de otras necrópolis de cistas en relación directa con la propia cuenca del río Ardila (fig. 1). Así, además de algunos hallazgos al E. de Las Arquetas, en el término municipal de Valencia del Ventoso, en dirección O. pueden apuntarse las de La Parrilla, Los Bolsiquillos, Dehesa Boyal, La Bóveda, Brovales y La Pizarrilla, todas ellas dentro del término municipal de Jerez de los Caballeros (fig. 1). No obstante, la información que hasta el momento han proporcionado es escasa y muy parcial, aunque pueden apuntarse ciertos aspectos de interés que impiden concebir la implantación de las necrópolis de cistas como un fenómeno de comportamiento uniforme. De las necrópolis citadas, la de Brovales fue objeto de excavaciones en los inicios de los años 80 , pero sus resultados permanecen aún inéditos.

Las cistas más cercanas a Las Arquetas son las de La Parrilla (fig. 1: $\mathrm{n}^{\circ}$ 2), a $5 \mathrm{kms}$. en línea recta y también en la margen izquierda del Ardila. En el lugar existió también una villa romana, lo que debió afectar al yacimiento prehistórico. A pesar de ello hay que anotar que las cistas repiten el patrón de situación visto en Las Arquetas, con una ubicación definida por el Alto de la Parrilla (425 m.) y el arroyo del mismo nombre, tributario del Ardila, entre el cauce del arroyo y el pie mismo de la ladera SE. del cerro. Como consecuencia de unos trabajos llevados a cabo allí en 1981 (Álvarez Sáenz de Buruaga y otros 1992) se conserva en el Museo de Badajoz un cráneo y diversos huesos que en absoluto conforman un esqueleto completo, pero ningún objeto de ajuar.

Aguas abajo, a 3,5 kms. en línea recta de La Parrilla y también en la margen izquierda, hay que apuntar el conjunto de cistas de Los Bolsiquillos (fig. 1: $\mathrm{n}^{\mathrm{o}} 3$ ), junto al cortijo del mismo nombre. Hoy han desaparecido en su mayor parte al estar dentro de una cochiquera, pero eran reconocibles diversas agrupaciones de cistas con diferente orientación, con técnicas constructivas y módulos similares a los de Las Arquetas. Su ubicación es igualmente al pie de un alto, pero en este caso una loma más pequeña y de menor altitud con respecto al entorno (354 m.), entre la caída NO. de ésta y el Ardila. A unos 300 $\mathrm{m}$. hay que destacar que se encuentra un sepulcro megalítico.

A 5,5 kms. en línea recta de los Bolsiquillos, pero en la margen derecha del Ardila, a 1,3 kms. de su cauce y sobre el pequeño valle que se extiende a la altura de La Bazana, se sitúa otro conjunto de cistas, el de la llamada Dehesa Boyal (fig. 1: $n^{\circ} 4$ ). Se trata en lo reconocible superficialmente de un grupo de al menos seis cistas y de otro probable de al menos tres, enclavado en la vertiente sur de una loma de $340 \mathrm{~m}$. de altitud, entre el pie de ésta y el arroyo de los Salores. El paisaje resulta aquí más abierto que en los lugares anteriores, caracterizado por dicho valle al que delimitan cerros y lomas que llegan a los $400 \mathrm{~m}$. También hay que destacar aquí la presencia de un sepulcro megalítico a unos $300 \mathrm{~m}$.

Más al O., a $12 \mathrm{kms}$. en línea recta de la Dehesa Boyal y a 9,5 kms. del cauce del Ardila, también en línea recta, está el conjunto de La Pizarrilla (fig. 1: $n^{\circ}$ 5), en el cortijo del mismo nombre. Allí se conservan algunas cistas que forman al menos dos conjuntos de dos, a los que hay que añadir otra más aislada, aparecida en la huerta, que cuando fue desmontada no proporcionó resto óseo alguno pero sí un vaso cerámico hoy perdido. Las cistas se ubican en la caída SE. de la loma en la que está el cortijo $(430 \mathrm{~m}$.), dentro de un paisaje cerrado por cerros, suaves lomas y algunas pequeñas sierras, entre las que destacan las de Nora $(466 \mathrm{~m}$.) al S. y Tinajas (469 m.) al N. A $370 \mathrm{~m}$. en dirección SE. están los restos de lo que Almagro Basch interpretó como el dolmen de La Pizarrilla (Almagro Basch 1963).

En la franja norte de este tramo del Ardila, en las salidas naturales septentrionales, hay que mencionar los conjuntos de cistas de Brovales y La Bóveda. El primero fue objeto de excavaciones, como se apuntó, y se encontraba al pie de la sierra de La Granja (439 m.), en el actual pantano de Brovales (fig. 1: $\mathrm{n}^{\circ}$ 6), dentro de un área de sierras junto al pasillo que abren los arroyos Tamujoso y Brovales hacia Salvatierra de los Barros y más al Este hacia Burguillos del Cerro. En la Bóveda (fig. 1: $\mathrm{n}^{\circ}$ 7), la situación de las cistas es también al pie de una sierra alta, pero a mitad de las elevaciones de la 
cumbre de S. José (728 m.), en la ruta que se abre hacia Barcarrota. Se trata de dos necrópolis separadas también, con grupos de cistas que han sido objeto de remociones. De una de ellas pudo recuperarse un vaso tipo Atalaia (fig.10: B) depositado en el Museo de Badajoz.

Estos conjuntos de cistas del entorno de Las Arquetas parecen reafirmar la relación entre la ubicación de estos cementerios y las rutas o caminos que allí confluyen, por un lado en dirección E.-O. a través de la propia ribera del Ardila, enlazando de este modo con las necrópolis del Bajo Alentejo (Parreira 1995), hasta el eje Viar-Bodión, que establece el paso a la cuenca del Guadalquivir. Por otro, en dirección N.-S. entre las estribaciones que conducen a la penillanura extremeña y los pasos a las sierras de Huelva, desde el núcleo distribuidor de Fregenal hacia Encinasola al SO., Jabugo y Cumbres al S. y el área de León al S. E.

En este sentido, recordemos cómo las Arquetas se sitúa en el camino que conduce desde Fregenal al vado del Ardila tras la desembocadura del Bodión, punto de enlace hasta la sierra de Tentudía y vía de comunicación con las franjas central y occidental de las estribaciones de la sierra Morena extremeña, con su correspondiente salida a la cuenca del Guadalquivir. Por su parte, La Parrilla está junto a un antiguo vado del Ardila, hoy desfigurado por el embalse de Valuengo, a través del cual se accedía a Burguillos del Cerro y zona de Zafra. Junto a los Bolsiquillos discurre la cañada real de Salvaleón, que aún cruza el Ardila por este punto. Por la Dehesa Boyal atraviesa el antiguo camino de Jerez a La Bazana salvando el Ardila. Estos cuatro puntos marcan por tanto pasos del río en dirección N.-S., en el tramo comprendido entre Valencia del Ventoso y Jerez de los Caballeros, que es a donde vienen a enlazar los caminos desde Fregenal. Y en su disposición E.-O. hay que resaltar cómo se insertan en intervalos de entre 3,5 y 5,5 kms. en línea recta, cubriendo los pequeños valles, como ocurre en la Dehesa Boyal, y las sierras destacadas, como Las Arquetas y La Parrilla. Los conjuntos más alejados del río: Valencia, Brovales y La Pizarilla no están a más de $15 \mathrm{kms}$. del río y se disponen en las salidas a Barcarrota, Salvaleón y Salvatierra de los Barros-Burguillos del Cerro-Zafra. No puede olvidarse tampoco cómo a una distancia en línea recta de $25 \mathrm{kms}$. de Las Arquetas se encuentran las necrópolis de cistas de la margen derecha del río Múrtiga (Pérez Macías 1987: 76).

Microespacialmente es clara también la preferencia por emplazamientos al pie de lomas, cerros y sierras de altitud diferente y con orientación distinta, con presencia también de cursos de agua secundarios. La disposición en dos necrópolis separadas como ocurre en Las Arquetas no se ha podido constatar más que en la Bóveda, pero a este nivel son totalmente desconocidas sus estructuraciones, así como sus densidades, aparentemente escasas. Por último, hay otro elemento que tal vez tenga también una significación o importancia destacada y que futuras investigaciones podrán contrastar. Es la relación espacial con sepulcros megalíticos. Recordemos cómo en Las Arquetas existe junto a la necrópolis 1 un sepulcro de galería, en los Bolsiquillos otro sepulcro a menos de $300 \mathrm{~m}$., que en la Dehesa Boyal ocurre los mismo, en la Pizarrila también y cerca de Brovales está la Granja del Toniñuelo (Carrasco 1991). No hay todavía documentación suficiente para establecer una relación clara entre ambas manifestaciones funerarias en el aspecto de su distribución espacial, pero tal vez deba ser tenida en cuenta a la hora de explicar sus ubicaciones y el funcionamiento espacial dentro de la articulación del territorio.

Con respecto a esta última cuestión, todavía no han sido localizados con seguridad poblados encuadrables en el segundo milenio a. C. ni en las prospecciones intensivas del entorno de Las Arquetas ni en las de las otras necrópolis. No puede apuntarse por tanto, al menos de momento, una dinámica ocupacional semejante a la detectada en ciertos puntos de las sierras onubenses (Hurtado 1993: 467). Por contra, sí se han reconocido poblados del Bronce final pero con elementos de cultura material muy característicos de dicho periodo y algunos otros aparentemente calcolíticos, que resultaría muy aventurado todavía ponerlos en relación con las necrópolis de cistas citadas y más aún porque no se encuentran en sus entornos inmediatos. 


\section{BIBLIOGRAFÍA}

ALMAGRO BASCH, M (1963): Excavaciones en el dolmen de La Pizarrilla, Jerez de los Caballeros. Trabajos de Prehistoria X. Madrid

ÁLVAREZ SÁENZ DE BURUAGA, J.; ÁLVAREZ MARTÍNEZ, J. M. y RODRÍGUEZ MARTÍN, G. (1992): La casa romana de El Pomar. Jerez de los Caballeros (Badajoz). Mérida

AUBET, M. E.; SERNA, R.; ESCACENA, J. L. y RUIZ DELGADO, M. M. (1983): La Mesa de Setefilla. Lora del Río (Sevilla). Campaña de 1979. Madrid.

CARMONA, M. A. (1993): Ganadería y vías pecuarias del sur de Extremadura durante la Baja Edad Media. Trashumancia y cultura pastoril en Extremadura. Villanueva de la Serena: 51-69

CARO, A. (1989): "Consideraciones sobre el Bronce antiguo y pleno en el Bajo Guadalquivir". Tartessos. Arqueología Protohistórica del Bajo Guadalquivir. Barcelona: 85-121.

CARRASCO, M. J. (1991): Avance al estudio del sepulcro megalítico de La Granja del Toniñuelo (Jerez de los Caballeros). Extremadura Arqueológica II: 113-129

DEL AMO, M. (1975): "Enterramientos en cista de la provincia de Huelva". Huelva, Prehistoria y Antigüedad. Madrid.

(1993): Formas y ritos funerarios en las necrópolis de cistas del suroeste peninsular. Spal 2: 169-183.

FERNÁNDEZ GÓMEZ, F.; RUIZ MATA, D. y DE SANCHA, S. (1976): "Los enterramientos en cistas del cortijo de Chichina (Sanlúcar la Mayor, Sevilla)". Trabajos de Prehistoria 33: 387-399.

GARCÍA GONZÁLEZ, L. (1994): Los ríos extremeños. Introducción a su régimen. Badajoz.

GARCÍA SANJUÁN, L. (1994): Registro funerario y relaciones sociales en el S. O. (1500-1100 a.n.e.): indicadores estadísticos preliminares. Arqueología en el entorno del Bajo Guadiana. Huelva: 209-239.

GIL MASCARELL, M.; RODRÍGUEZ DÍAZ, A. y ENRÍQUEZ, J. J. (1986): Enterramientos en cistas de la Edad del Bronce en la Baja Extremadura. Sagumtum 20: 9-43.

GUERRA, A. y MONTURIOL, F. (1968): Explicación del mapa provincial de suelos. Madrid.

HURTADO, V. (1993): Análisis y definición de los procesos culturales del II milenio A.C en el suroeste peninsular. Investigaciones Arqueológicas en Andalucía. 1985-1992. Proyectos. Huelva: 461-471.

- y GARCÍA SANJUÁN, L. (1994): "Áreas funcionales en el poblado de la Edad del Bronce de El Trastejón (Zufre, Huelva). Campaña de 1991", Arqueología en el entorno del Bajo Guadiana. Huelva: 239-243.

PARREIRA, R. (1995): “Aspectos da Idade do Bronze no Alentejo interior”, A Idade do Bronze em Portugal. Discursos de poder. Lisboa.

PAVÓN, I. (1993): La Solana del castillo de Alange: un yacimiento de la Edad del Bronce en la cuenca media del Guadiana. Spal 2: 147-169.

(1995a): El tránsito del II al I milenio A. C. en las cuencas medias de los ríos Tajo y Guadiana: La Edad del Bronce. Tesis Doctoral (inédita). Cáceres.

- (1995b): Bases estratigráficas para una revisión cronológica del Bronce del Suroeste: el corte 3 de la Umbría del cerro del castillo de Alange. Homenaje a la Dra. Milagro Gil Mascarell. Extremadura Arqueológica V: 81-97

PAVÓN, I.; LÓPEZ CARBALLO; J. L. y PLAZA, F. (1993): “Las Minitas (Almendralejo, Badajoz): una necrópolis de cistas del Bronce del Suroeste en la Tierra de Barros (Campaña de urgencia de 1994)", Norba 13: 11-36.

PÉREZ MACÍAS, A. (1987): Carta Arqueológica de los picos de Aroche. Higuera de la Sierra.

- y RUIZ DELGADO, M. M. (1986): "Otras necrópolis de cistas de la provincia de Huelva", Huelva en su Historia I. Huelva. 
— y FRÍAS, C. (1990): "La necrópolis de cistas de la Parrita (Nerva, Huelva) y los inicios de la metalurgia de la plata en las minas de Riotinto". Cuadernos del Suroeste 1: 11-22.

RIVAS GODAY, S. (1964): Vegetación y Florura de la Cuena extremeña del Guadiana. Madrid.

RUIZ-GÁLVEZ, M. (1984): La Península Ibérica y sus relaciones con el círculo cultural atlántico. Madrid.

SCHUBART, H. (1965): "Atalaia. Uma necropole da Idade do Bronze no Baixo Alemtejo". Arquivo de Beja 22: 7-136.

— (1971): “Acerca de la cerámica del Bronce tardío en el Sur y Oeste Peninsular”. Trabajos de Prehistoria 28: 153-183.

— (1975a): Die Kultur der Bronzezeit im Südwestwen der Iberischen Halbinsel. Berlín.

— (1975b): "Cronología relativa de la cerámica sepulcral en la cultura de El Argar", Trabajos de Prehistoria 32: 79-93.

TAVARES DA SILVA, C. y SOARES, J. (1979): "O Monumento I da necropole do Bronze do Sudoeste do P.....gueiro (Sines)". Setúbal Arqueológica V: 121-148

- (1981): Prehistoria da area de Sines. Sines.

VARELA GOMES, M. y otros (1986): A necropole da Vinha do Casao (Villamoura, Algarve) no contexto da Idade do Bronze do Sudoeste peninsular. Lisboa.

VV. AA. (1987a): Mapa geológico-minero de Extremadura. Consejería de Industria y Energía. Junta de Extremadura. Madrid.

VV. AA. (1987b): La minería en Extremadura. Consejería de Industria y Energía. Junta de Extremadura. Madrid. 

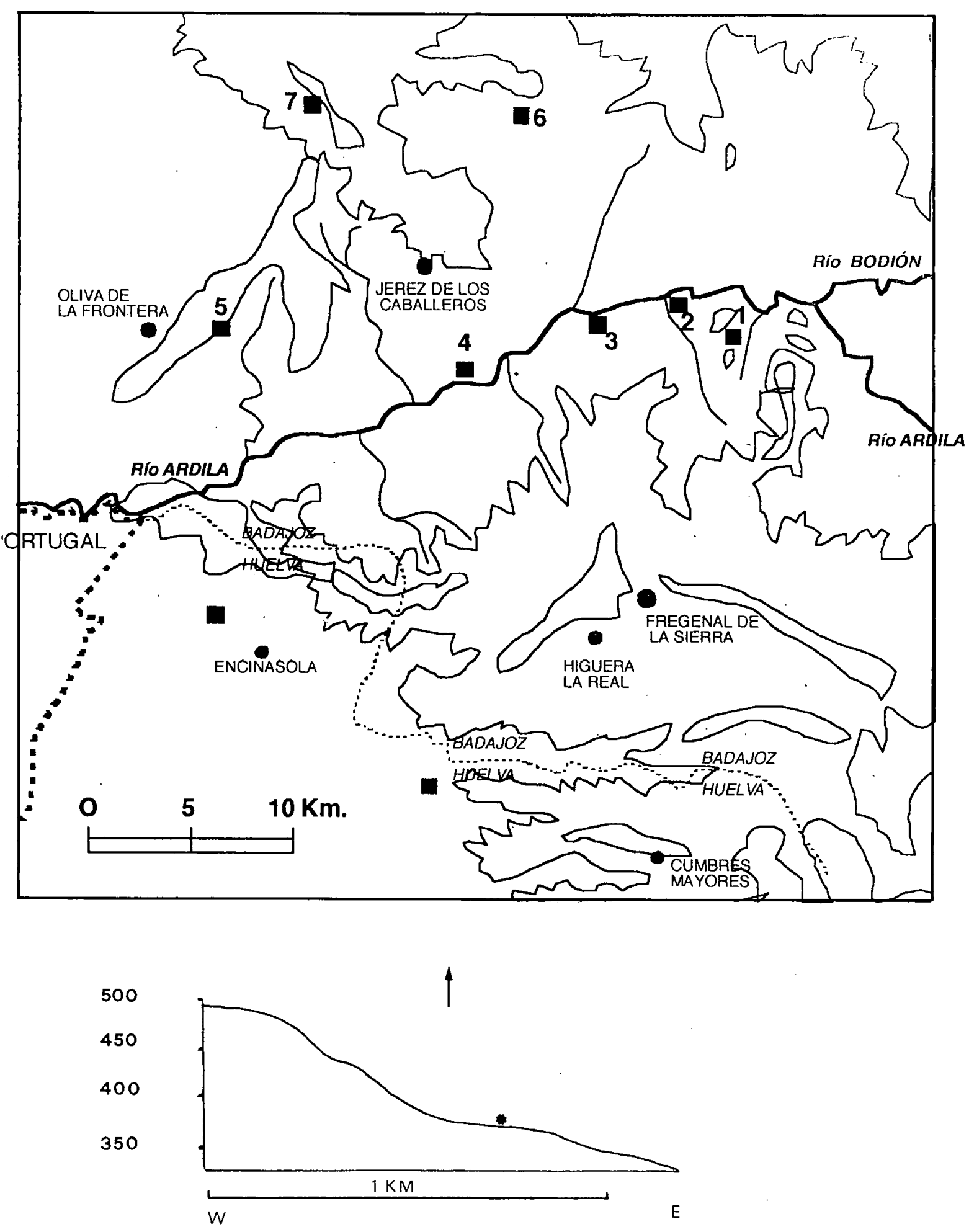

Figura 1. Situación de Las Arquetas $\left(n^{\circ} 1\right)$ y otros grupos de cistas del entorno del Ardila. Corte topográfico del terreno a la altura de Las Arquetas. 


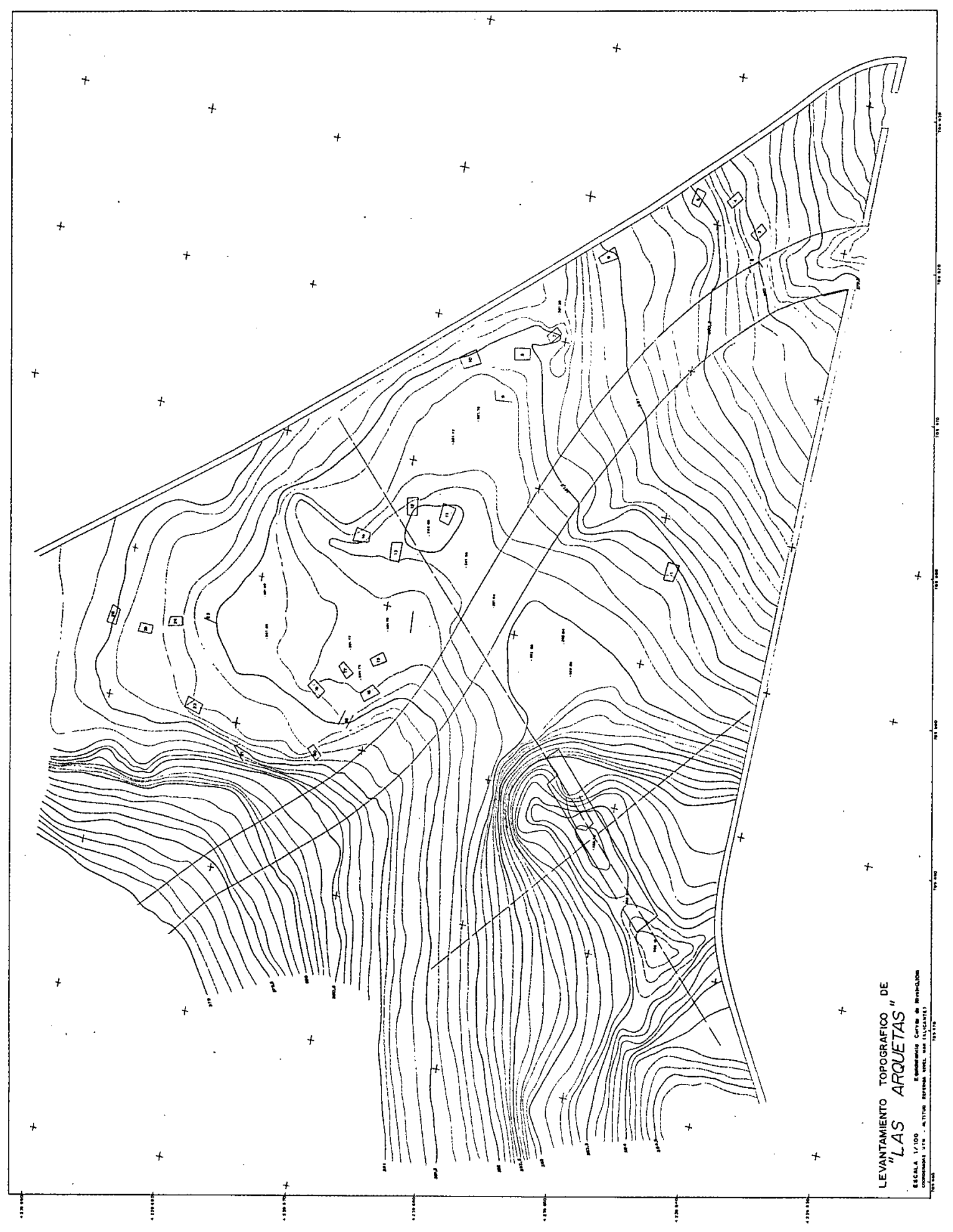

Figura 2. Plano de Arquetas 1 


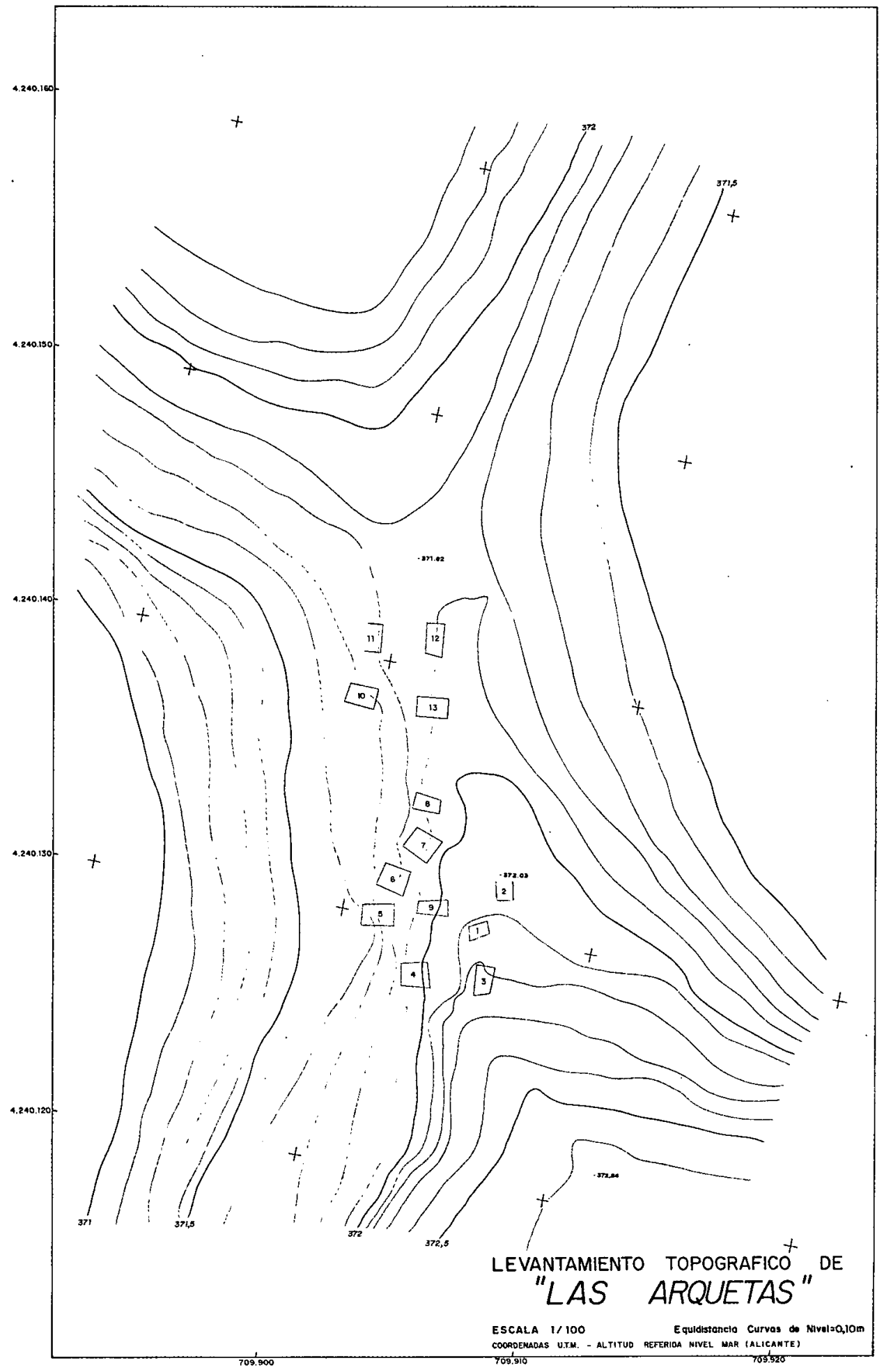

Figura 3. Plano de Arquetas 2 

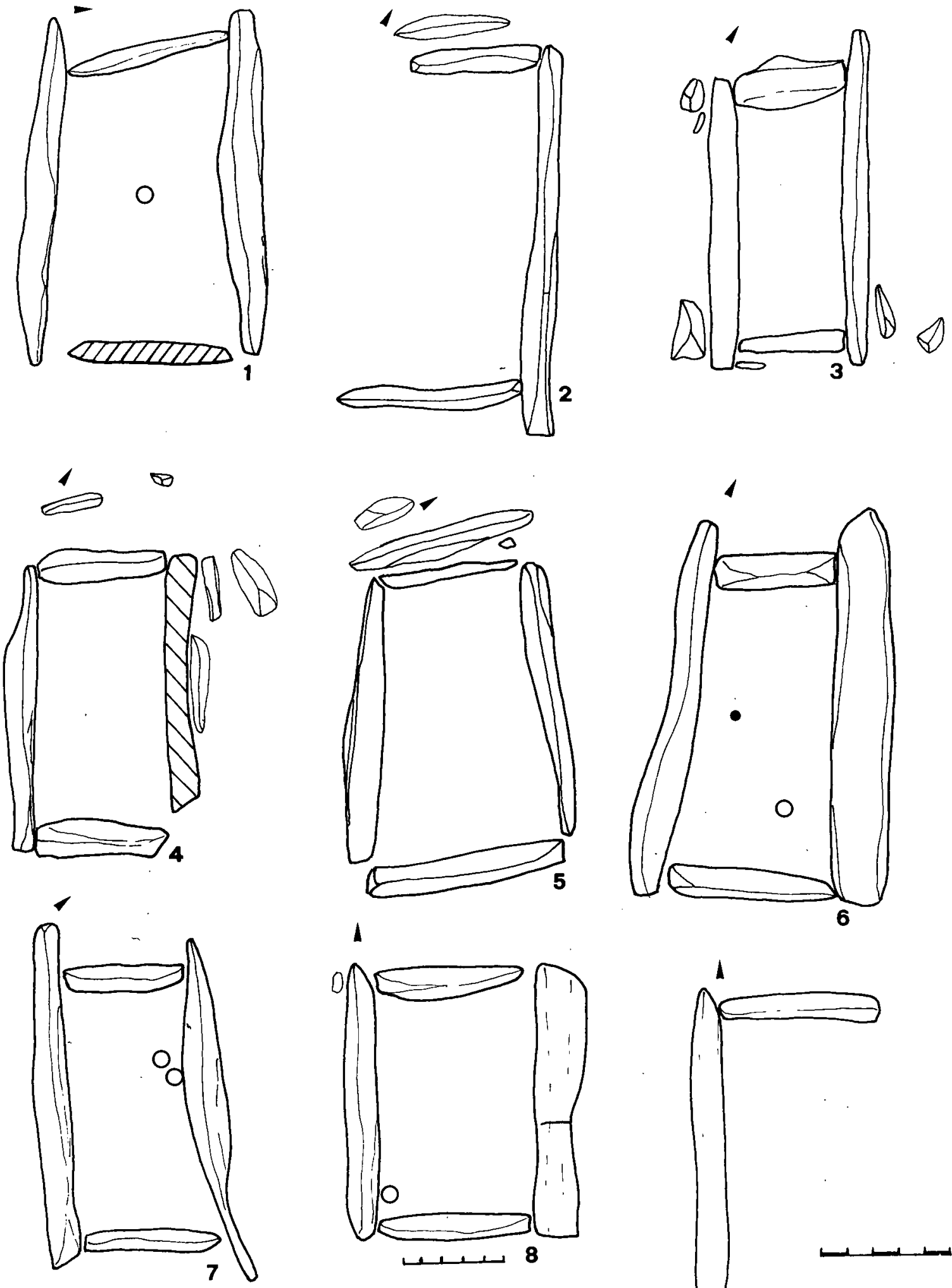

Figura 4. Plantas de cistas de Arquetas 1 (n 1-9) 

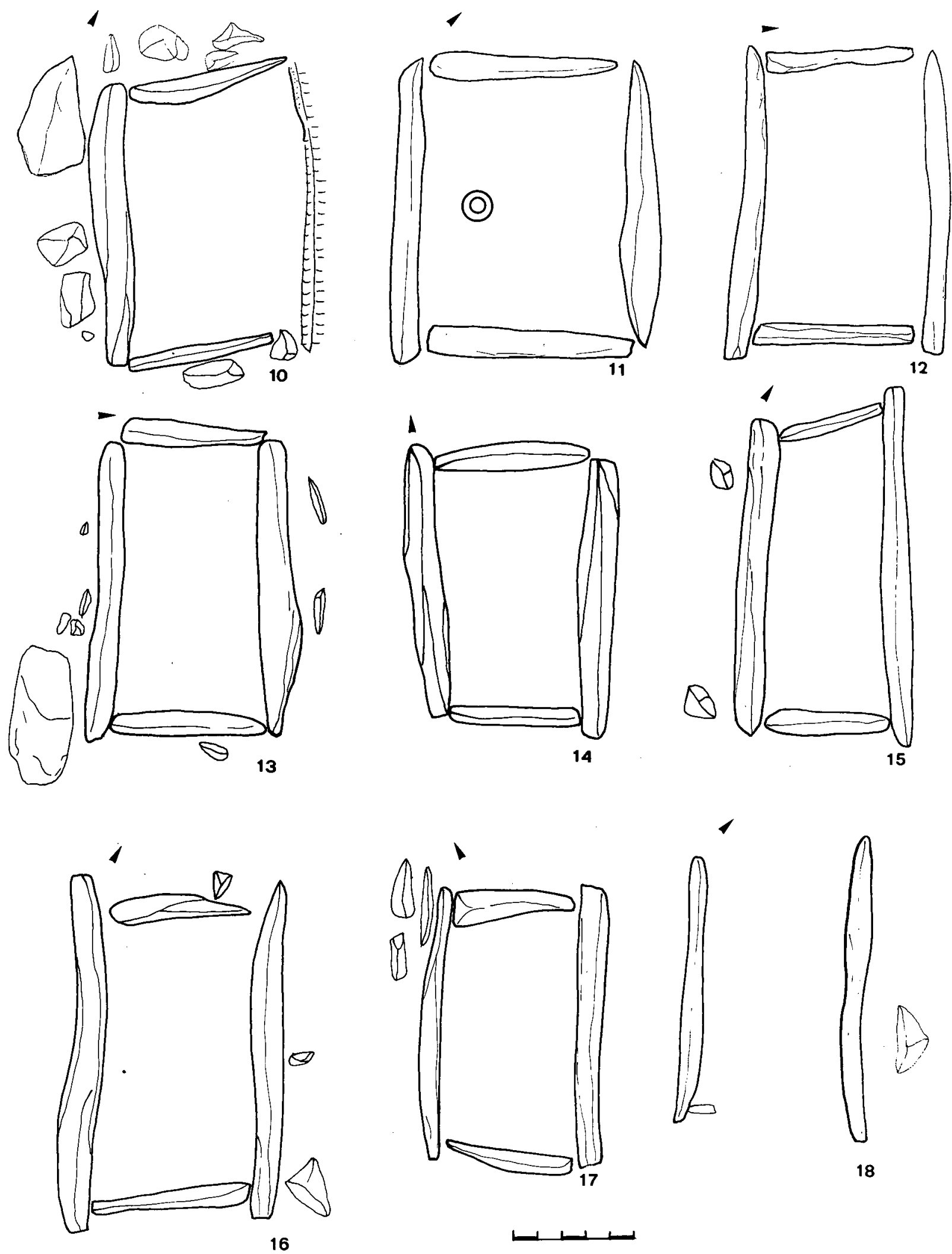

Figura 5. Plantas de cistas de Arquetas $1\left(n^{\circ} 10-18\right)$

ISSN: 1133-4525 ISSN-e: 2255-3924 

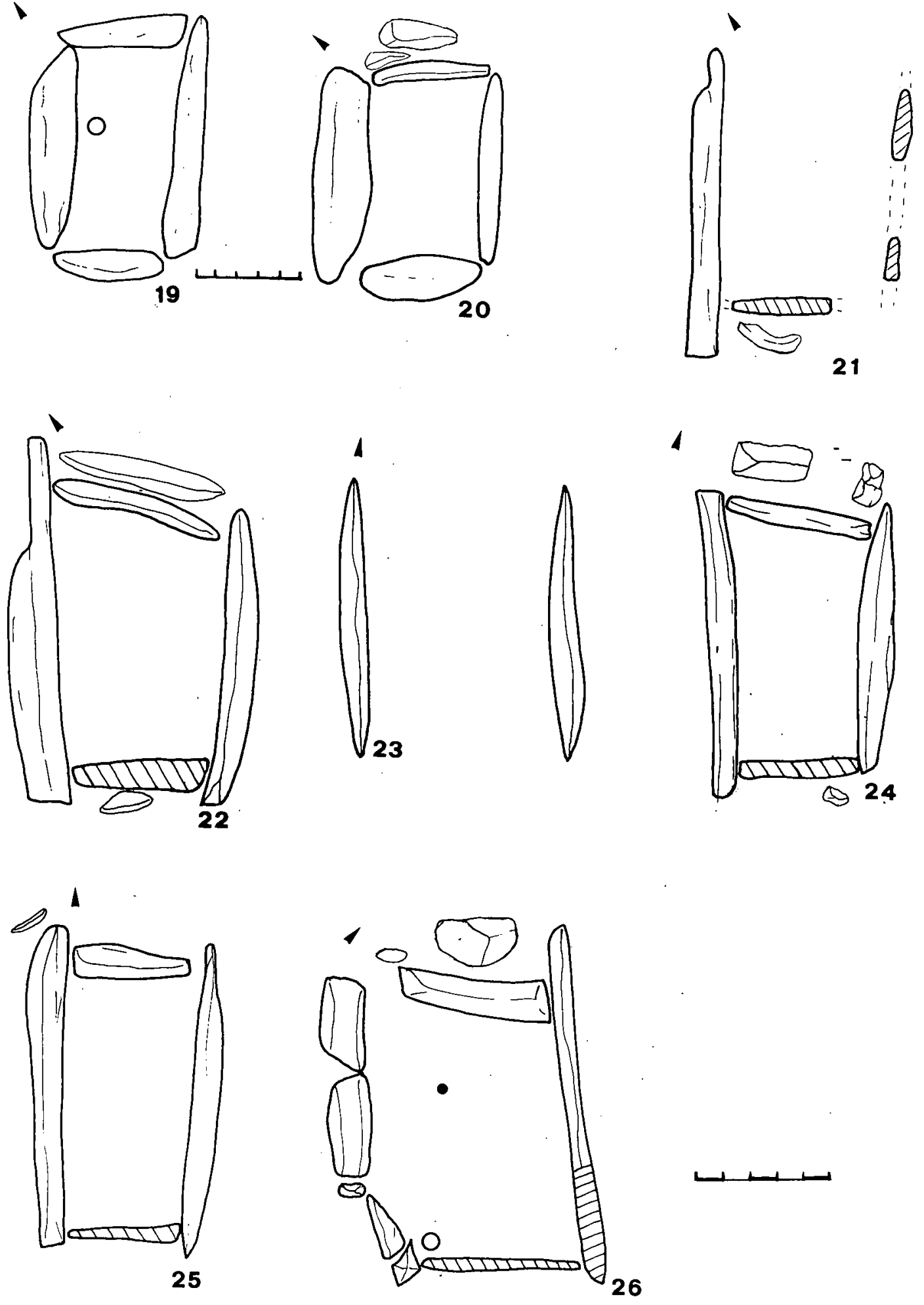

Figura 6. Plantas de cistas de Arquetas 1 ( $\left.\mathrm{n}^{\circ} 19-26\right)$ 

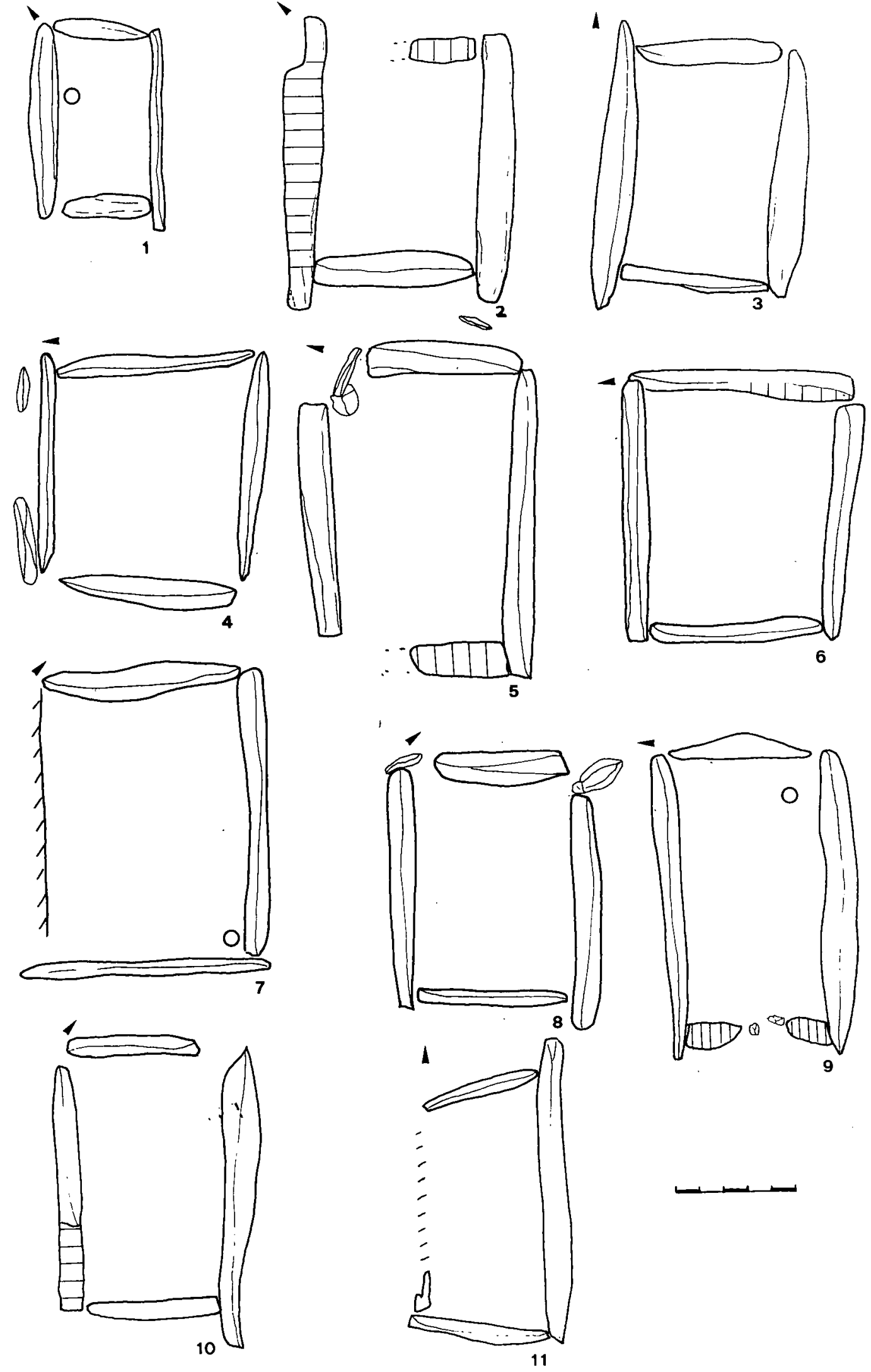

Figura 7. Plantas de cistas de Arquetas $2\left(\mathrm{n}^{\circ} 1-11\right)$ 

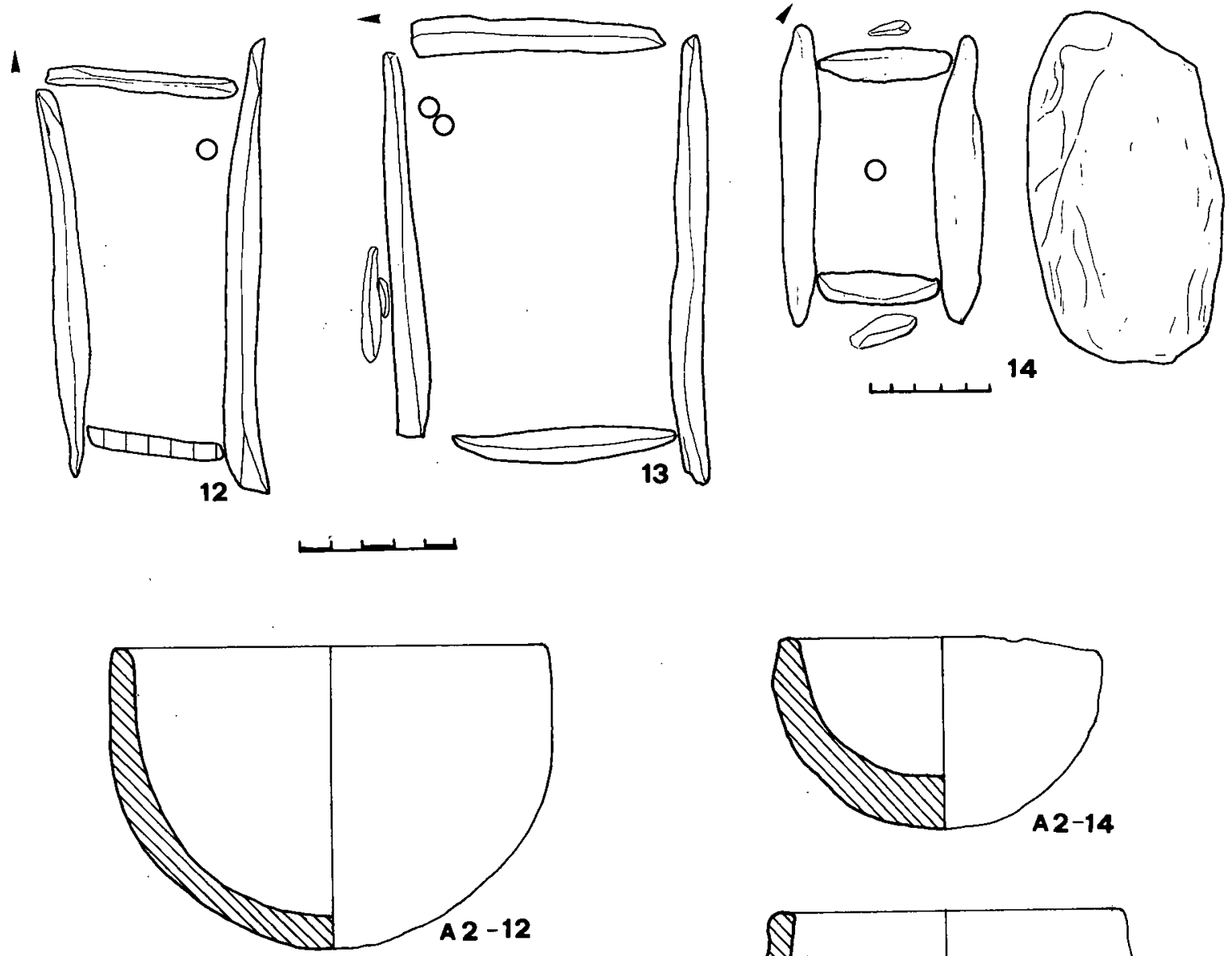

A 2-12
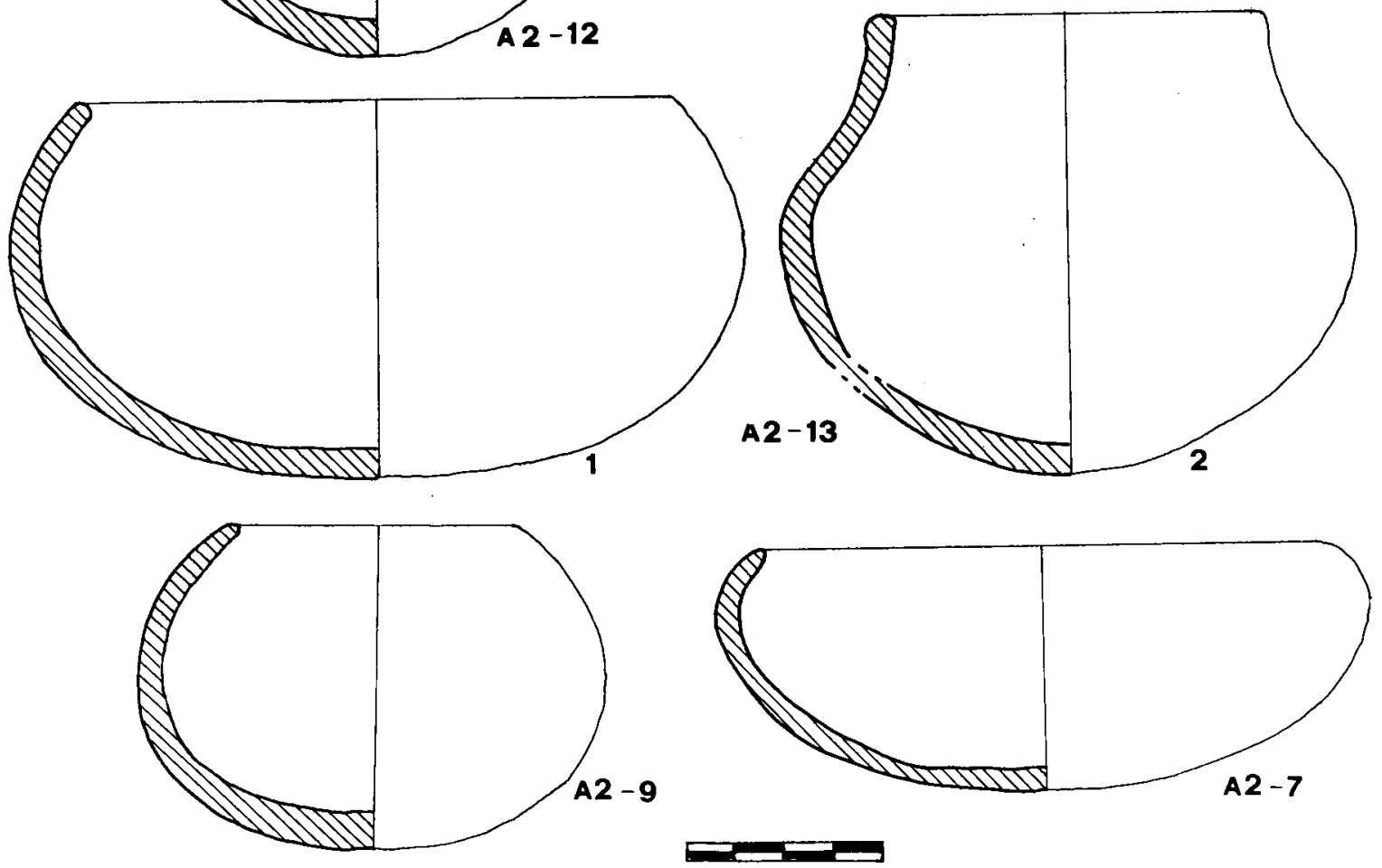

Figura 8. Plantas de cistas de Arquetas $2\left(n^{\circ} 12-14\right)$ y ajuares 

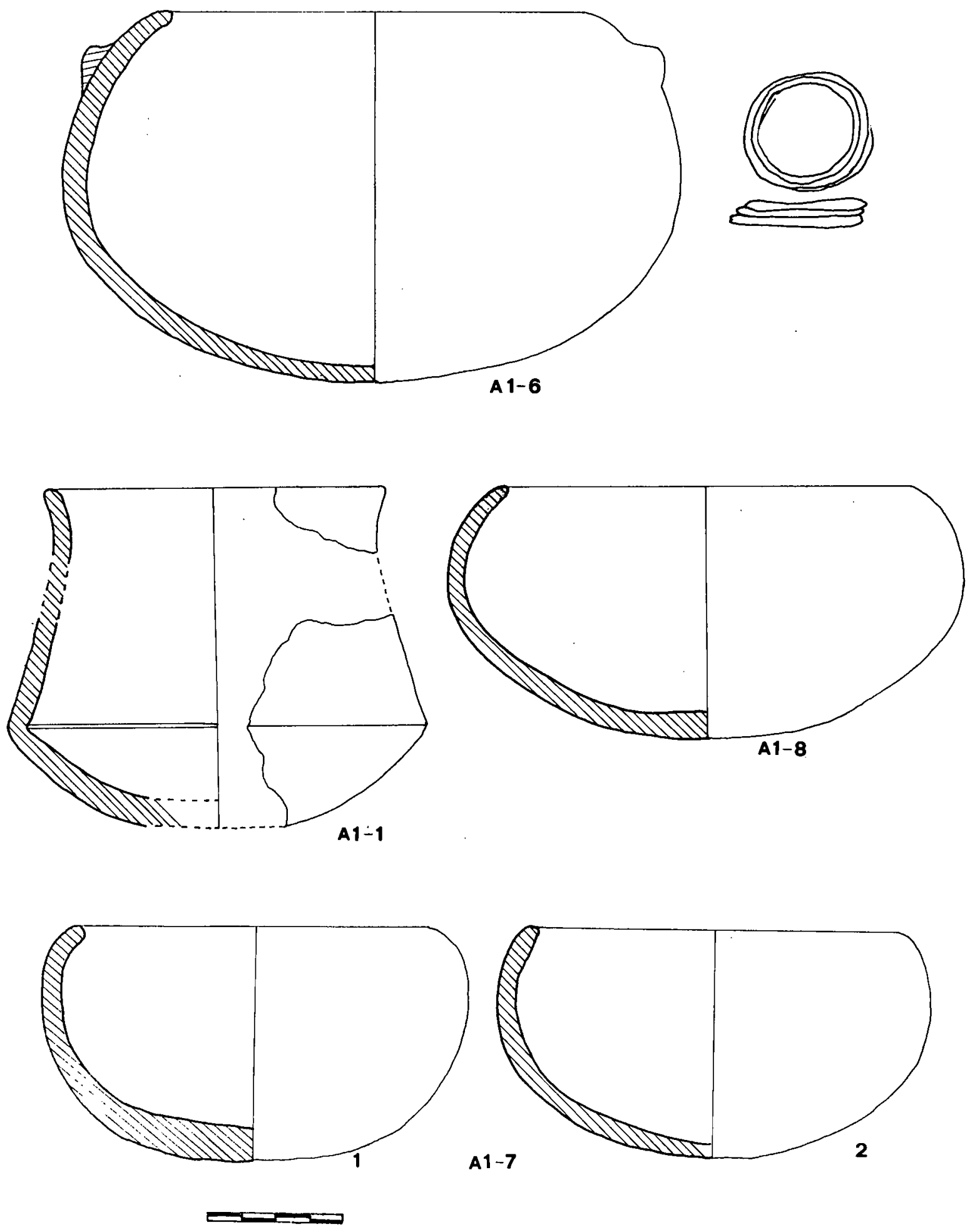

Figura 9. Ajuares de Arquetas 1 

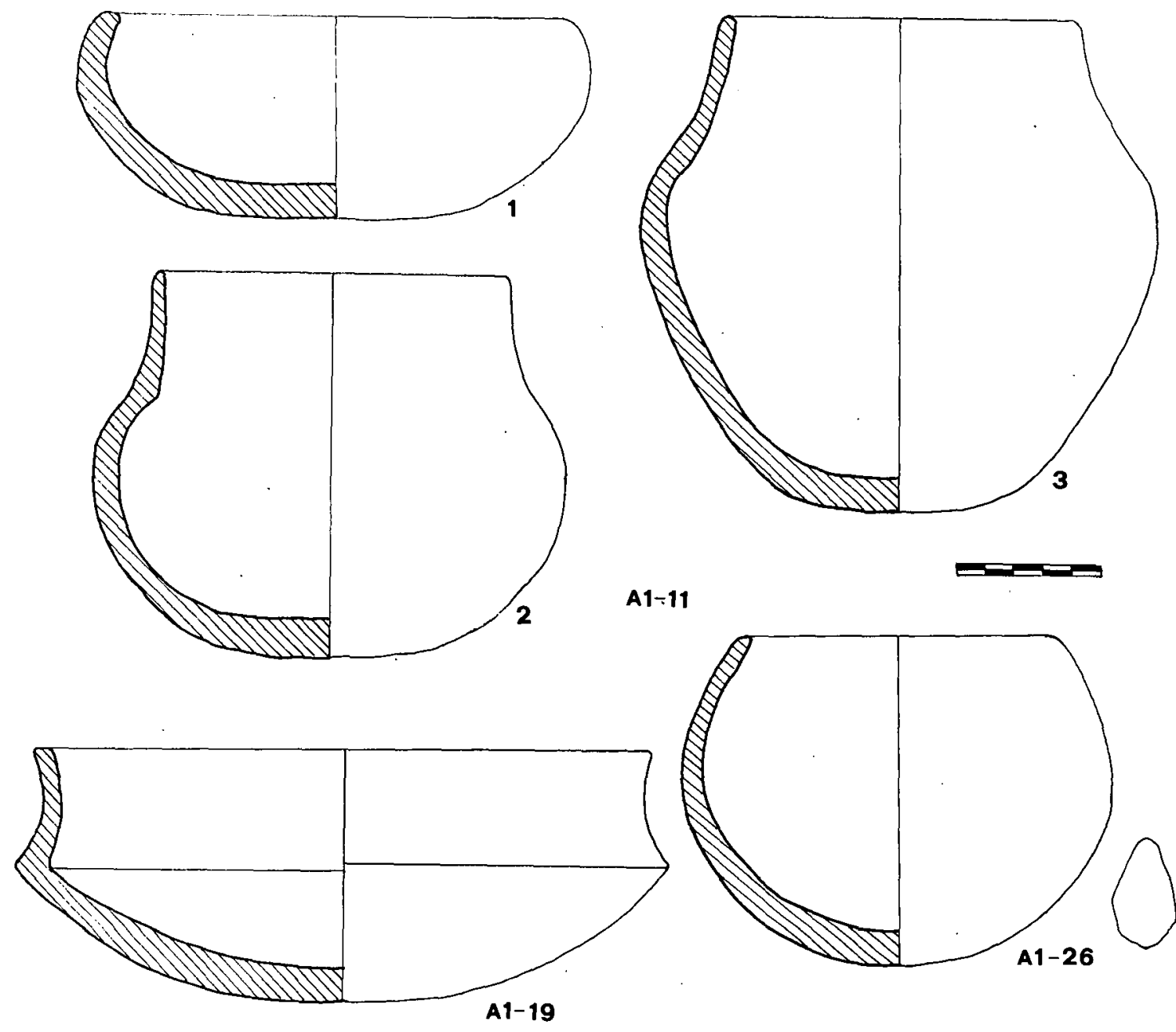

A1-11
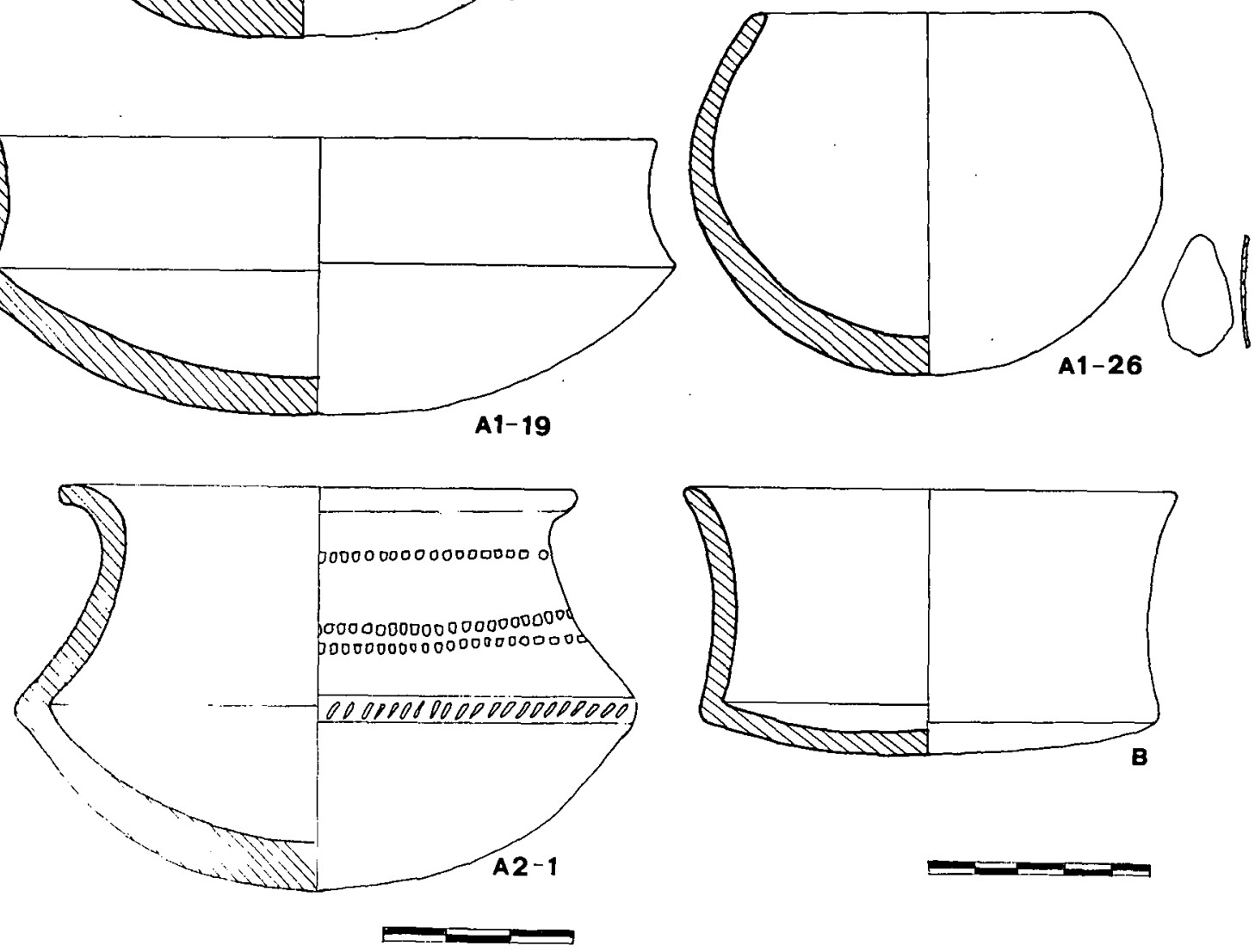

Figura 10. Ajuares de Arquetas 1, vaso decorado de cista 1 de Arquetas 2 y vaso de la Bóveda 

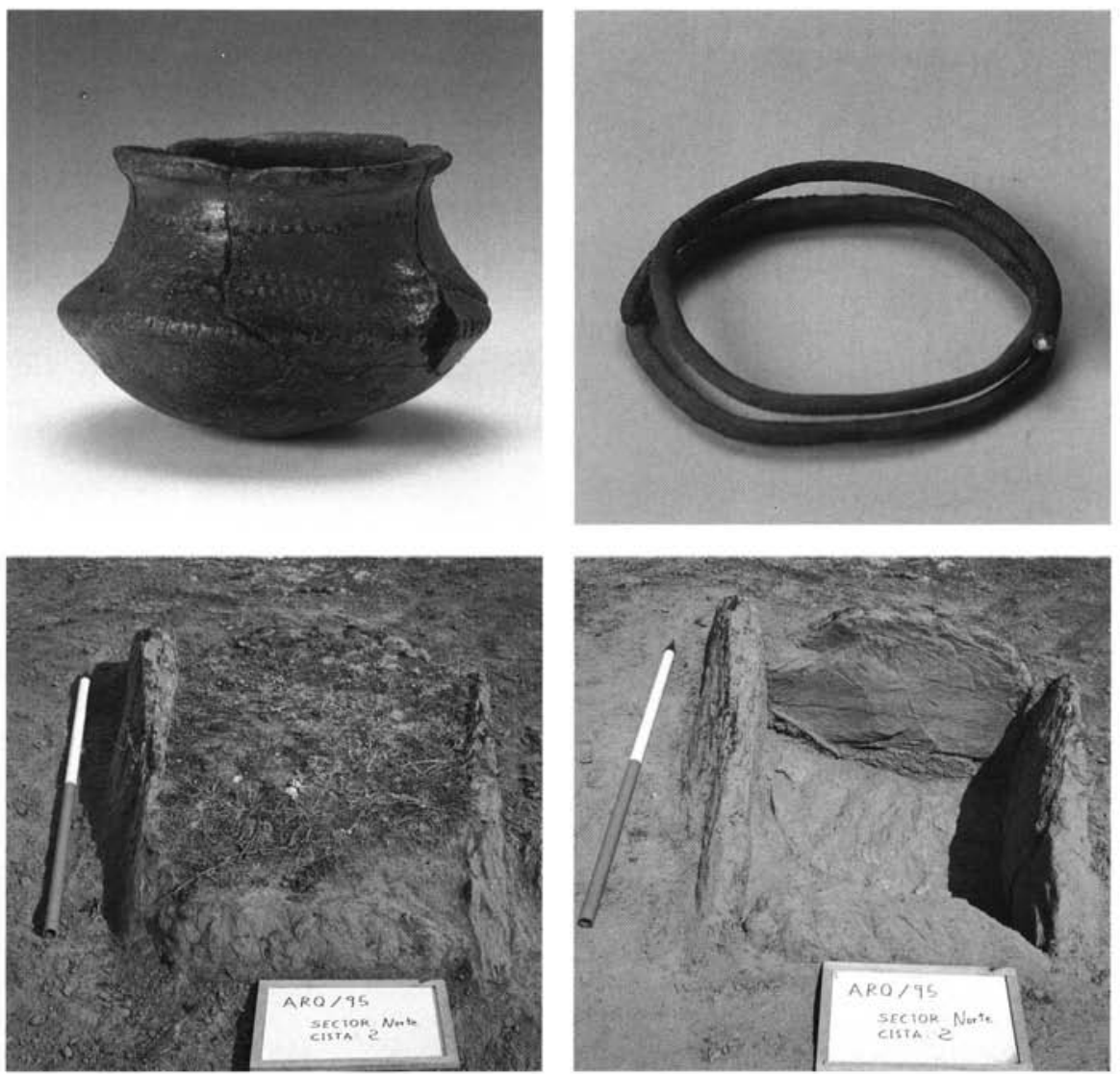

Lámina: 1. Vaso decorado de la cista 1 de Arquetas 2; espiral de plata de la cista 6 de Arquetas 1; cista tipo antes y después de su excavación. 